\title{
Effect of isothiocyanates, BITC and PEITC, on stress protein accumulation, protein aggregation and aggresome-like structure formation \\ in Xenopus A6 kidney epithelial cells
}

\author{
Imran Khamis and John J. Heikkila \\ Department of Biology, University of Waterloo \\ Waterloo, ON \\ Canada N2L 3G1
}

*Corresponding author:

Dr. John J. Heikkila

Department of Biology, University of Waterloo,

Waterloo, ON

Canada N2L 3G1

Tel: 519-888-4567 Ext. 33076

FAX: 519-746-0614

heikkila@uwaterloo.ca 


\begin{abstract}
Numerous studies have elucidated the health benefits of organosulfur compounds, known as isothiocyanates (ITCs), derived from cruciferous vegetables. As electrophiles, ITCs have the ability to directly bind and modify thiol-containing compounds such as glutathione and cellular protein, including tubulin. While the biochemical effects of ITCs have been well characterized, less information is available regarding their effects on the accumulation of stress-inducible heme oxygenase-1 (HO-1), heat shock proteins (HSPs) and the possible formation of aggregated protein due to thiol modification. The present study has examined the effect of the ITCs, benzyl isothiocyanate (BITC) and phenethyl isothiocyanate (PEITC), on the accumulation of HO-1, HSP70 and HSP30 in Xenopus laevis A6 kidney epithelial cells. Immunoblot analysis revealed that both BITC and PEITC induced the accumulation of HO-1 and HSP70 whereas HSP30 levels were enhanced only in cells treated with BITC. Immunocytochemistry determined that ITC treatment induced F-actin disorganization and membrane ruffling and enhanced accumulation of HO-1 in the cytoplasm. Additionally, BITC induced enhanced levels of ubiquitinated protein, aggregated protein, and the collapse and fragmentation of microtubules. In comparison, treatment of cells with the proteasomal inhibitor, MG132, induced the accumulation of all three stress proteins, aggregated protein and aggresome-like structures. Finally, cells pretreated with BITC inhibited the formation of MG132-induced aggresome-like structures in the perinuclear region. This latter finding suggests that BITC-induced microtubule fragmentation may impede the movement of aggregated protein via microtubules and their subsequent coalescence into aggresome-like structures in the perinuclear region.
\end{abstract}

Key Words: Amphibian, frog, heme oxygenase-1, isothiocyanates, protein aggregates, aggresomes, heat shock protein, MG132 


\section{Introduction}

Organosulfur compounds known as isothiocyanates (ITCs) occur naturally as glucosinolates in cruciferous vegetables (Molina-Vargas, 2013). Treatment of plants with physical stress such as biting or chewing, activates myrosinase, an enzyme which hydrolyzes glucosinolates into ITCs (Zhang et al., 2006). Since ITCs are electrophilic, they can readily form conjugates with thiols as well as covalently bind glutathione and cellular protein including tubulin (Li et al., 2012). Numerous studies have reported human health promoting properties of ITCs such as their chemopreventive efficacy and possible prevention of neurodegenerative diseases (Zhang et al., 2006; Mi et al., 2007; 2008; 2009; 2010; Li et al., 2012; Mi et al., 2011; Sarkars et al., 2013; Giacoppo et al., 2015). Two of the most extensively studied ITCs are benzyl isothiocyanate (BITC) and phenethyl isothiocyanate (PEITC).

Given the importance and abundance of tubulin within the cell, any chemical modification of the protein by ITCs could result in a significant conformational change. In fact, tubulin modification was suggested as being the main mechanism through which BITC and PEITC induced cell cycle arrest and apoptosis leading to the suppression of mammalian oncogenic cells (Zhang et al., 2006; Sarkars et al., 2013). A previous study found that thiol side chains of cysteine residues of $\alpha$ - and $\beta$-tubulin were prone to modification by BITC and to a lesser extent PEITC (Mi et al., 2008). Additionally, it was shown that BITC had a more pronounced effect on inducing proteasomal inhibition than PEITC. Since BITC is a

smaller compound, containing a methyl group extending from its aromatic hydrocarbon compared to an ethyl group for PEITC, it has greater accessibility to cysteine residues buried within the tubulin molecule thus increasing its affinity for the protein (Mi et al., 2008). Nevertheless, both ITCs inhibited proteasome protease activities by direct covalent interaction with thiol groups within the catalytic active site of proteasome subunits. 
An increase in our knowledge of the effects of ITCs is important given their potential role as therapeutic compounds in the treatment of cancer, neurodegenerative diseases and bacterial and viral infections (Dufour et al., 2013; Morris et al., 2014; Giacoppo et al., 2015). While studies in mammalian systems have characterized the ability of ITCs to directly bind and modify thiol-containing proteins including $\alpha$-tubulin, less is known regarding their ability to induce the accumulation of stress proteins such as heme oxygenase (HO-1) and heat shock proteins (HSPs) or their impact on the F-actin and microtubule cytoskeleton. Stress-inducible HO-1, also known as HSP32, catalyzes the catabolism of heme to iron, carbon monoxide and biliverdin (Tenhunen et al., 1968; Ryter et al., 1999; Gozzelino et al., 2010; Correa-Costa et al., 2012). HO-1, which is found in every cell, is essential for human health since its deficiency is characterized by growth retardation, hemolytic anemia, endothelial damage, iron deposition and increased vulnerability to oxidative stress-related injury (Yachie et al., 1999; Chau, 2015). In mammalian systems, a variety of inducers including curcumin, MG132, sodium arsenite, and cadmium were reported to induce ho- 1 gene expression (Alam et al., 2000; Wu et al., 2004; Yamamoto et al., 2010; Wang et al., 2013). Stress-induced ho- 1 gene expression is controlled primarily at the transcriptional level (Ryter et al., 2006). The primary transcription factor responsible for expression of the ho-1 gene is the nuclear factor erythroid 2 (NFE2)-related factor 2 (Nrf2; Choi et al., 2014). Regarded as a member of the leucine zipper transcription factors, Nrf2 is supressed under basal conditions as it is bound to Kelch-like ECH-associated protein 1 (Keap1). Stress-induced modification of cysteine residues results in Keap1 dissociating from Nrf2, which then translocates into the nucleus. Subsequently, Nrf2 forms a heterodimer with Maf protein before binding to the antioxidant response element to induce ho-1 gene expression (Choi et al., 2014).

In mammalian cells, both BITC and PEITC were found to induce the accumulation of the heat shock protein, HSP70 (Naidu et al., 2016). The heat shock response is a universal cellular 
cytoprotective mechanism that results in the accumulation of HSPs including HSP90, HSP70 and small HSPs, which are molecular chaperones that confer resistance against proteotoxic stress induced by elevated temperatures, heavy metals, oxidants or disease states (Verghese et al., 2012). Stress-induced accumulation of unfolded protein triggers the activation and binding of heat shock factor 1 (HSF1) to the heat shock element (HSE), an enhancer situated in the upstream promoter region of $h s p$ genes (Morimoto, 1998; 2008, Xie et al., 2014). The primary role of HSPs is to bind unfolded protein and prevent the formation of toxic protein aggregates. However, some stressors, such as sodium arsenite in high concentrations, can cause a large increase in the amount of unfolded or misfolded proteins and overwhelm the molecular chaperone system leading to the formation of toxic protein aggregates (Del Razo et al., 2001; Liu et al., 2001; Samuel et al., 2005; Brunt et al., 2012; Khan et al., 2015). Furthermore, an impairment of the ubiquitin proteasome system, which is the primary system for the degradation of damaged protein, can further exacerbate this situation. In order to isolate and minimize the effect of toxic protein aggregates, the cell sequesters these aggregates into aggresome-like structures encased within a vimentin cage (An and Statsyuk, 2015). Studies with proteasomal inhibitors such as MG132 have demonstrated that this process occurs through a microtubule-dependent process, which involves the transport of aggregated protein along microtubule networks using dynein motors to the perinuclear region and their subsequent proteolysis by autophagy (Uversky and Fink, 2007; Zaarur et al., 2008; Bolhuis and Richter-Landsberg, 2010; Xiong et al., 2013; Khan et al., 2014).

Xenopus laevis adults, embryos and cultured cells have been extensively used as model systems in cell and molecular biology research. Much of the information obtained from studies with Xenopus is applicable to humans. A6 kidney epithelial cells, derived from Xenopus laevis proximal renal tubules, was used to study the expression of various stress proteins including the accumulation of HO-1 in response to cadmium, arsenite and proteasomal inhibitors (Music et al., 2014; Shirriff et al., 2017). 
This cell line has been vital in the analysis of Xenopus HSP70 and HSP30 accumulation after treatment with various environmental stressors including heat shock, sodium arsenite and cadmium chloride (Ohan et al., 1998; Gellalchew and Heikkila, 2005; Woolfson and Heikkila, 2009; Heikkila, 2010; Brunt et al., 2011; Khamis and Heikkila, 2013). Xenopus HSP70 is a stress-inducible molecular chaperone that inhibits aggregation of unfolded protein and can refold protein in an ATP-dependent manner (Heikkila, 2010). HSP30 is the major stress-inducible sHSP in Xenopus but has counterparts in other frogs as well as fish and birds but not mammals (Helbing et al., 1996; Norris et al., 1997; Katoh et al., 2004; Elicker and Hutson, 2007; Mulligan-Tuttle and Heikkila, 2007; Heikkila, 2017). As a molecular chaperone, HSP30 can bind to stress-induced unfolded protein, inhibit their aggregation and maintain them in a folding competent state (Fernando and Heikkila, 2000; Abdulle et al., 2002; Fernando et al., 2002; 2003). Also, studies with Xenopus A6 cells revealed that that HSP30 colocalized with aggresome-like structures in response to certain stressors such as MG132, arsenite and cadmium as well as recovery from heat shock (Khan and Heikkila, 2014; Khan et al., 2015; Shirriff and Heikkila, 2017).

In the present study, we investigated the effect of BITC and PEITC on HO-1, HSP70 and HSP30 accumulation as well as the impact of these ITCs on the F-actin and microtubule structure using immunoblot and/or immunocytochemical analyses. Additionally, we determined the effect of BITC on the levels of ubiquitinated protein as well as the accumulation of aggregated protein and aggresomelike structures. Finally, the effect of BITC treatment on MG132-induced formation of aggresomes was determined. 


\section{Materials and methods}

\subsection{Maintenance and treatment of Xenopus laevis A6 cells}

Xenopus laevis A6 kidney epithelial cells were obtained from the American Type Culture Collection (Rockville, MD). The cell line was grown in 70\% Leibovitz L-15 Media containing 10\% fetal bovine serum and 1\% penicillin/streptomycin (Sigma-Aldrich, Oakville, ON) at $22^{\circ} \mathrm{C}$ in $\mathrm{T} 75 \mathrm{~cm}$ BD falcon culture flasks (VWR, Mississauga, ON) as described previously (Khamis and Heikkila, 2013; Khan and Heikkila, 2014). A6 cells were treated with 5, 7.5 or $10 \mu \mathrm{M}$ BITC or 5 or $7.5 \mu \mathrm{M}$ PEITC at 22 or $30{ }^{\circ} \mathrm{C}$ in a water bath. BITC and PEITC were dissolved in dimethyl sulphoxide (DMSO) to make a stock solution of $100 \mathrm{mM}$ from which a $1 \mathrm{mM}$ working solution was created. Exposure of cells to DMSO alone did not induce stress protein accumulation or change levels of $\alpha$ tubulin or actin (data not shown). In some experiments, carbobenzoxy-L-leucyl-L-leucinal (MG132; Sigma-Aldrich; dissolved in DMSO), a reversible proteasomal inhibitor, was added to the cells at a final concentration of $30 \mu \mathrm{M}$. At the end of the various treatments, A6 cells were harvested and stored at $-80{ }^{\circ} \mathrm{C}$.

\subsection{Protein isolation and immunoblot analysis}

Total protein was isolated from A6 cells as described by Young et al. (2009). Briefly, protein was isolated using $300 \mu \mathrm{L}$ lysis buffer (200 mM sucrose, 2 mM EGTA, 1 mM EDTA, 40 mM NaCl, 30 mM HEPES, pH 7.4), which contained 1\% SDS and 1\% protease inhibitor cocktail (Promega; Madison, WI). For ubiquitinated protein, $10 \mathrm{mM}$ N-ethylmaleimide (Sigma-Aldrich) was added to the lysis buffer to inhibit deubiquitination of proteins. Samples were sonicated on ice with a sonic dismembranator (Model 100, Fisher Scientific; Waltham, MA, USA) and then centrifuged at 14,000 rpm for $30 \mathrm{~min}$ at $4{ }^{\circ} \mathrm{C}$. Protein supernatants were isolated and stored at $-20^{\circ} \mathrm{C}$ until further use. The bicinchoninic acid method was used for protein quantification according to the manufacturer's 
instructions (Pierce, Rockford, IL, USA). Thirty micrograms of protein were subjected to SDS-PAGE employing $12 \%$ polyacrylamide gels for HO-1, HSP70, HSP30 and $\alpha$-tubulin using a BioRad Miniprotein III gel system (BioRad, Mississauga, ON). Analysis of actin levels used $12 \mu \mathrm{g}$ of protein. Determination of ubiquitinated protein levels by SDS-PAGE utilized $60 \mu \mathrm{g}$ of protein in conjunction with $10 \%$ polyacrylamide gels. After SDS-PAGE, protein samples were transferred to a nitrocellulose membrane (BioRad) with a Trans-Blot Semi-dry Transfer cell (BioRad). Ponceau S (Sigma-Aldrich) staining of the membrane was employed to assess the efficiency of transfer of each sample. Immunodetection of HO-1 employed a rabbit anti-HO-1 antibody (dilution of 1:500; Enzo Life Sciences, Farmingdale, NY; Catalog No. BML-HC3001-0100) that was made against a synthetic peptide that shared 100\% identity with X. laevis HO-1 (Music et al., 2014; Shirriff and Heikkila, 2017). Other antibodies used in this study included rabbit polyclonal anti-Xenopus HSP70 (1:350 dilution; Gauley et al., 2008), anti-Xenopus HSP30 (1:500 dilution; Fernando and Heikkila, 2003), and anti-actin (1:200 dilution; Sigma-Aldrich; Catalog No. A2066) as well as monoclonal mouse anti- $\alpha$-tubulin antibody (1:500 dilution; Sigma; Catalog No. T9026) and anti-ubiquitin (1:150; Invitrogen, Carlsbad, CA; Catalog No. 13-1600). Membranes were incubated with secondary antibody in blocking solution for $1 \mathrm{~h}$ including alkaline phosphatase-conjugated goat-anti-rabbit (Sigma-Aldrich; Catalog No. A3687) at a dilution of 1:30,000 dilution, which was used to detect HO-1, HSP70, HSP30 and actin while alkaline phosphatase-conjugated goat-anti-mouse (BioRad; Catalog No. 1706520) at a 1:1000 dilution was used to monitor $\alpha$-tubulin and ubiquitin. For detection, blots were immersed in alkaline phosphatase detection buffer (50 mM Tris, $50 \mathrm{mM} \mathrm{NaCl}, 25 \mathrm{mM} \mathrm{MgCl}_{2} \mathrm{pH} 9.5$ ) with $0.3 \%$ 4-nitro blue tetrazolium and $0.17 \%$ 5-bromo-4-chloro-3-indolyl phosphate, toluidine salt. 


\subsection{Densitometry and statistical analysis}

Densitometric analysis of all blots were performed with at least 3 separate replicates, using Image J software (Version 1.44; National Institute of Health http://rsb.info.nih.gov/ij/). The average densitometric values of HO-1, HSP70 or HSP30, within the range of linearity, were expressed as a percentage of the maximum signal obtained for each stress protein. The densitometric values obtained for $\alpha$-tubulin or ubiquitin were compared to control. The standard error is represented by vertical error bars. To determine if any statistically significant differences existed between samples, a one-way ANOVA with a Tukey's post-test was performed on the data.

\subsection{Immunocytochemistry and laser scanning confocal microscopy}

Immunofluorescence analysis was performed as previously described (Gellalchew and Heikkila, 2005; Manwell and Heikkila, 2007; Khamis and Heikkila, 2013, Khan et al., 2015). A6 cells were grown on flame sterilized base-washed glass coverslips in sterile plates for 24 to $48 \mathrm{~h}$. Cells were treated with BITC, PEITC or MG132 as previously described in section 2.1. Following the treatments, cells were rinsed twice with phosphate buffered saline (PBS) and fixed with 3.7\% paraformaldehyde (BDH, Toronto, ON) for 15 min followed by 3 washes with PBS. Cells were permeabilized using 0.3 \% Triton X-100 (Sigma-Aldrich) for $10 \mathrm{~min}$. After an additional 3 washes with PBS, A6 cells were incubated with 3.7\% (w/v) bovine serum albumin (BSA; Sigma-Aldrich) overnight at $4{ }^{\circ} \mathrm{C}$. Cells were then incubated with rabbit anti-HO-1 (1:200), rabbit anti-Xenopus HSP30 (1:500) or monoclonal mouse anti- $\alpha$-tubulin (1:250) antibodies in 3.7\% BSA for $1 \mathrm{~h}$. After three washes for 3 min each with PBS, indirect labeling of cells was carried out with fluorescent-conjugated secondary antibodies including goat anti-rabbit Alexa Fluor 488 (Molecular Probes) at a 1:1000 dilution or goat anti-mouse Alexa Fluor 488 (Invitrogen Molecular Probes) at 1:1000 in 3.7\% BSA for 30 min in the dark. Cells were then incubated with rhodamine-tetramethylrhodamine-5-isothiocyanate phalloidin (TRITC; 
Invitrogen Molecular Probes) for $15 \mathrm{~min}$ at a 1:60 in 3.7\% BSA in the dark in order to visualize the Factin cytoskeleton. A ProteoStat aggresome detection kit (Enzo Life Sciences, Plymouth Meeting, PA) was used to monitor the presence of aggregated protein and/or aggresome-like structures as per manufacturer's instructions. Coverslips were dried and mounted on a glass microscope slide with Vectashield (Vector Laboratories Inc., Burlingame, CA) containing 4,6-diamidino-2-phenylindole (DAPI; Vector Laboratories Inc.) to stain nuclei followed by three washes of 5 min each. Clear nail polish was used to permanently attach coverslips to glass slides and the slides were stored at $4{ }^{\circ} \mathrm{C}$. Slides were examined using a Zeiss Axiovert 200 confocal microscope with Zen 2009 software (Carl Zeiss Canada Ltd., Mississauga, ON).

\section{Results}

\subsection{Immunoblot analysis of HO-1, HSP70 and HSP30 accumulation in BITC-and PEITC-treated} Xenopus A6 cells.

In this study, the effect of BITC on the relative levels of HO-1, HSP70 and HSP 30 at $22^{\circ} \mathrm{C}$ was examined. As shown in Figure 1, treatment of cells with 5 or $7.5 \mu \mathrm{M}$ BITC for $12 \mathrm{~h}$ resulted in greater accumulation of HO-1 compared to control than found with $10 \mu \mathrm{M}$ BITC. In cells treated with $5 \mu \mathrm{M}$

BITC, HSP70 was induced to relatively low levels relative to cells that were exposed to either 7.5 or 10 $\mu \mathrm{M}$ BITC at $22{ }^{\circ} \mathrm{C}$. Also, very low levels of HSP30 were induced in cells treated with all three concentrations of BITC at $22^{\circ} \mathrm{C}$. Time course experiments determined that maximal levels of these stress proteins occurred after 12-16 h of $7.5 \mu \mathrm{M}$ BITC treatment (data not shown). Given that HSP70 and HSP30 are heat-inducible, HO-1 and HSP levels were examined in A6 cells treated with BITC at a higher incubation temperature of $30^{\circ} \mathrm{C}$. Densitometric analysis revealed that A6 cells treated with 5 or 
$7.5 \mu \mathrm{M}$ BITC at $30{ }^{\circ} \mathrm{C}$ had HO-1 levels that were 56 and $28 \%$ less, respectively, than found with treatments at $22{ }^{\circ} \mathrm{C}$. However, treatment of cells with BITC at $30{ }^{\circ} \mathrm{C}$ produced an increase in both HSP70 and HSP30 accumulation relative to the responses observed at $22{ }^{\circ} \mathrm{C}$ or with $30^{\circ} \mathrm{C}$ alone. Densitometric analysis revealed that treatment of cells with $7.5 \mu \mathrm{M}$ BITC at $30^{\circ} \mathrm{C}$ resulted in a 40 -fold increase in HSP30 compared to the responses obtained with the same concentration of BITC at $22{ }^{\circ} \mathrm{C}$ or with $30{ }^{\circ} \mathrm{C}$ alone. Lower concentrations of BITC (less than $5 \mu \mathrm{M}$ ) did not induce HSP70 or HSP30 accumulation (data not shown). Throughout these experiments, the levels of actin remained relatively constant. The next set of experiments examined the effect of different concentrations of PEITC on HO1, HSP70 and HSP30 accumulation at 22 and $30{ }^{\circ} \mathrm{C}$ for $12 \mathrm{~h}$. As shown in Figure 2, higher levels of HO-1 and HSP70 accumulation were observed in cells treated with $5 \mu \mathrm{M}$ PEITC at $22{ }^{\circ} \mathrm{C}$ compared to cells treated with $7.5 \mu \mathrm{M}$. Exposure of cells to $5 \mu \mathrm{M}$ PEITC at $30{ }^{\circ} \mathrm{C}$ resulted in a 59 and $58 \%$ decrease in HO-1 and HSP70 accumulation, respectively, compared to values obtained at $22{ }^{\circ} \mathrm{C}$. A decrease in HO-1 levels, but not HSP70, was evident in cells treated with $7.5 \mu \mathrm{M}$ PEITC at $30^{\circ} \mathrm{C}$ compared to 22 ${ }^{\circ} \mathrm{C}$. HSP30 accumulation was not detected in response to PEITC treatment at either temperature. The levels of actin remained relatively constant throughout these experiments. In separate experiments, it was determined that BITC- and PEITC-induced accumulation of HO-1 and HSPs was the result of $d e$ novo transcription and translation since pretreatment of cells with either $2 \mu \mathrm{g} / \mathrm{mL}$ actinomycin $\mathrm{D}$ or 100 $\mu \mathrm{M}$ cycloheximide inhibited their accumulation (data not shown).

\subsection{F-actin cytoskeletal structure and localization of HO-1 in BITC-and PEITC-treated cells.}

Immunocytochemistry and laser scanning confocal microscopy (LSCM) was used to compare the effect of BITC and PEITC on F-actin cytoskeletal structure and HO-1 localization in A6 cells. As shown in Figure 3, cells incubated at 22 or $30{ }^{\circ} \mathrm{C}$ displayed F-actin stress fibers transversing the entire 
length of cells in mostly axial bundles with the appearance of a few radial bundles located at the periphery. Treatment of A6 cells with BITC resulted in the presence of ruffled edges in some cells. When BITC treatment was performed at $30^{\circ} \mathrm{C}, \mathrm{F}$-actin cytoskeletal disorganization (yellow arrows) was observed in the periphery of cells. Additionally, some BITC-treated cells at 22 or $30^{\circ} \mathrm{C}$ displayed F-actin cytoskeletal collapse around the nucleus resulting in smaller diameter cells. Following PEITC treatment at $22{ }^{\circ} \mathrm{C}$, slight membrane ruffling was localized to the periphery of most cells (Fig. 4). In these experiments, F-actin disorganization was enhanced when A6 cells were incubated with PEITC at $30{ }^{\circ} \mathrm{C}$. Immunocytochemical analysis of HO-1 revealed that treatment of cells with $7.5 \mu \mathrm{M}$ BITC at 22 ${ }^{\circ} \mathrm{C}$ induced the accumulation of $\mathrm{HO}-1$ in $85 \%$ of cells in a punctate pattern that was enriched in the perinuclear region of the cytoplasm with some staining in the nucleus (Fig. 3). Treatment of cells with BITC at $30{ }^{\circ} \mathrm{C}$ resulted in $70 \%$ of cells displaying a punctate pattern of $\mathrm{HO}-1$ accumulation with larger staining structures present at the cell periphery in $30 \%$ of cells (white arrows). Following $5 \mu \mathrm{M}$ PEITC treatment at 22 and $30{ }^{\circ} \mathrm{C}, 80 \%$ and $75 \%$ of cells, respectively displayed $\mathrm{HO}-1$ accumulation primarily in the perinuclear region of the cytoplasm in a punctate pattern (Fig. 4).

\subsection{Relative levels of ubiquitinated and aggregated protein accumulation in BITC-treated cells.}

Previous studies determined that in contrast to PEITC, BITC had a greater ability to modify protein thiol groups and induce the accumulation of ubiquitinated protein in mammalian systems (Mi et al., 2008; 2009; 2010; Xiao et al., 2012). Therefore, it was possible that BITC could induce an accumulation of ubiquitinated and possibly aggregated protein in amphibian cells. Exposure of A6 cells to BITC for $12 \mathrm{~h}$ at $22{ }^{\circ} \mathrm{C}$ resulted in a $50 \%$ increase in ubiquitinated protein accumulation while BITC treatment at $30^{\circ} \mathrm{C}$ resulted in levels of ubiquitinated protein that were comparable to control (Fig. 5). A ProteoStat aggresome detection assay was used to examine the effect of BITC on protein aggregation 
and aggresome formation in $\mathrm{A} 6$ cells. Cells maintained at $22{ }^{\circ} \mathrm{C}$ displayed minimal staining with the ProteoStat dye while BITC treatment resulted in a punctated pattern of aggregated protein throughout the cytoplasm (Fig. 6). Furthermore this treatment did not induce detectable accumulation of HSP30. In contrast, cells treated with MG132 resulted in the accumulation of aggregated protein as well as the formation of numerous and intensely stained aggresome-like structures (approximately $30-50$ per cell) in the perinuclear regions, which co-localized with HSP30 as determined by Z-stacking analysis. In these immunocytochemical analyses, HSP70 was not examined because the affinity-purified antiXenopus HSP70 antibody, which was employed successfully in immunoblot analysis, did not specifically detect HSP70 by immunochemistry (Gauley et al., 2008; Khan and Heikkila, 2014).

\subsection{Time course of the effect of BITC on microtubule and F-actin cytoskeletal structure and $\alpha$-tubulin levels.}

Since previous studies determined that BITC can bind and modify thiols associated with tubulin dimers (Mi et al., 2008; 2009), the next set of experiments utilized immunocytochemistry and LSCM to investigate changes in cytoskeletal structure over time in cells treated with BITC. As shown in Figure 7, a control-like pattern of F-actin cytoskeletal structure was found in A6 cells that were exposed to $4 \mathrm{~h}$ of BITC at $22{ }^{\circ} \mathrm{C}$. However, after 8 and $12 \mathrm{~h}$ of BITC treatment, membrane ruffling was observed in the cell periphery (yellow arrows). As previously mentioned, BITC induced actin cytoskeletal collapse in some cells (Fig. 7; white asterisks). In contrast to the F-actin cytoskeleton, BITC-induced microtubule fragmentation was visible after $1 \mathrm{~h}$ (data not shown) and easily detectable after 4 and $8 \mathrm{~h}$ (white arrows). After $12 \mathrm{~h}$ of BITC treatment at $22{ }^{\circ} \mathrm{C}$, a coalescence of the microtubules in the perinuclear region was apparent (white arrow). Given this effect of BITC on the microtubule network, immunoblot analysis was performed to characterize the effect of BITC on $\alpha$-tubulin levels in A6 cells. As shown in Figure 8, treatment of cells with BITC for 4,8 or $12 \mathrm{~h}$ at $22{ }^{\circ} \mathrm{C}$ produced a decline in $\alpha$ - 
tubulin levels relative to control. Densitometric analysis revealed that cells treated with BITC for $4 \mathrm{~h}$ resulted in a $61 \%$ decrease in $\alpha$-tubulin levels relative to control and a $91 \%$ decrease at $12 \mathrm{~h}$.

\subsection{BITC pretreatment inhibited the formation of MG132-induced aggresome-like structures in A6 cells.}

Since previous results revealed that BITC induced microtubule fragmentation, it was possible that this phenomenon could potentially disrupt the movement of aggregated protein to the perinuclear region, which is involved in the formation of aggresomes. As shown in Figure 9, treatment of cells with MG132 for $12 \mathrm{~h}$ at $22{ }^{\circ} \mathrm{C}$ resulted in intact microtubules and the formation of large aggresome-like structures (green arrows; $30-50$ per cell) that localized primarily to the perinuclear region. However, a $2 \mathrm{~h}$ BITC pretreatment prior to the introduction of MG132 induced the fragmentation of microtubules (white arrows) and reduced the intensity, size and the number of aggresome-like structures (10-15 per cell). When the pretreatment time was lengthened to $4 \mathrm{~h}$, microtubule fragmentation became more pronounced, and the number of MG132-induced large aggresome-like structures was less than 10 per cell, many of which were not located within the perinuclear region of A6 cells.

\section{Discussion}

The present study has investigated, for the first time in a poikilothermic vertebrate model system, the effect of the ITCs, BITC and PEITC, on the accumulation of the stress proteins HO-1 and HSPs as well as their impact on cytoskeletal structure and aggregated protein accumulation. In studies performed with X. laevis A6 kidney epithelial cells, it was determined that HO-1 accumulation was readily induced by BITC and PEITC. This finding was in agreement with previous studies performed with human cell lines including prostate and liver cancer cells (Xu et al., 2006; Prawan et al., 2007). It has been proposed in mammalian cells that BITC- and PEITC-induced HO-1 accumulation occurs in response to their rapid and prolonged binding and inactivation of glutathione, a key antioxidant, which 
can trigger the oxidative stress pathway (Mi et al., 2007). Transcriptional activation of ho-l gene expression in response to oxidative stress conditions involves the activation of $\mathrm{Nrf2}$, the principal regulator of ho-1 gene induction (Alam et al., 2000; Suzuki et al., 2003; Waisberg et al., 2003; Galazyn-Sidorczuk et al, 2009). Alternatively, it was suggested that BITC-induced proteasomal inhibition resulted in Nrf2 stabilization leading to the upregulation of ho-1 gene expression (Stewart et al., 2003; Kobayashi, 2004; Martin et al., 2004; Mi et al., 2008; 2011; Choi et al., 2014). While the exact mechanism for ITC-induced HO-1 accumulation in A6 cells is not known, it is likely that one or both of the aforementioned pathways may be involved. Exposure of cells to BITC or PEITC at $30^{\circ} \mathrm{C}$ produced lower HO-1 levels than observed at $22{ }^{\circ} \mathrm{C}$. This finding was in contrast to other stressors such as cadmium or arsenite, which induced enhanced levels of HO-1 at an elevated incubation temperature in A6 cells (Music et al., 2014). The reason for these differences is not known at this time.

Both BITC and PEITC induced an increase in HSP70 levels in A6 cells. These results are in accordance with a study examining the effect of BITC and PEITC on HSP70 accumulation in mammalian cell lines (Naidu et al., 2016). Since ITCs are electrophilic, it is possible that their interaction with cysteine thiol side chains found in hydrophobic pockets of targeted proteins resulted in conformational changes and/or protein unfolding and led to the activation of the heat shock response pathway (Mi et al., 2008). In contrast to HSP70, treatment of A6 cells with BITC induced very low levels of HSP30 while undetectable amounts were observed after PEITC exposure. Previous studies in our laboratory have shown that the accumulation of HSP30 and HSP70 by heavy metals, proteasomal inhibitors or metalloids was enhanced by an elevated incubation temperature of $30^{\circ} \mathrm{C}$ (Woolfson and Heikkila, 2009; Young et al., 2009; Khan and Heikkila, 2011; Khamis and Heikkila, 2013). An elevated incubation temperature of $30^{\circ} \mathrm{C}$ enhanced HSP70 and HSP30 levels in BITC treated-cells and HSP70 in cells exposed to PEITC. It is possible that the amount of BITC-induced unfolded and/or 
damaged protein which resulted from proteasomal inhibition or covalent interactions with thiol groups of cellular protein was enhanced at the higher incubation temperature leading to a stronger activation of HSF1 and a greater accumulation of HSP70 and HSP30 (Young et al., 2009; Khamis and Heikkila, 2013; Heikkila, 2017). However, the reason for the differences in the ability to detect HSP70 and HSP30 accumulation following PEITC treatment at $30^{\circ} \mathrm{C}$ is not known although differences in the relative level of different HSPs in response to various stressors in A6 cells have been reported (Gauley and Heikkila, 2008; Young et al., 2010; Walcott and Heikkila, 2010; Khan et al., 2011).

Immunocytochemical analysis determined that BITC and PEITC induced the accumulation of HO-1 primarily in the cytoplasmic perinuclear region in a punctate pattern with some $\mathrm{HO}-1$ present in the nucleus. It has been reported that in response to certain stressors (e.g. hypoxia or hemin) mammalian HO-1, which is normally attached to the smooth endoplasmic reticulum membrane by means of its C-terminal tail, is severed by a protease releasing HO-1 into the cytoplasm followed by its translocation to the nucleus or mitochondria (Converso et al., 2006; Slebos et al., 2007; Lin et al., 2007; Gandini et al., 2012; Namba et al., 2014). In A6 cells treated with BITC at $30^{\circ} \mathrm{C}$, accumulation of HO1 was detected throughout the cytoplasm and in the nucleus in a punctate pattern whereas with PEITC treatment at $30^{\circ} \mathrm{C}$ HO-1 accumulation occurred primarily in the perinuclear region. While the reason for this difference is not known, PEITC was determined to be a weaker inducer of protein modification, mitotic arrest, and HO-1 accumulation than BITC (Mi et al., 2008; 2009; 2010). Given the strong activity of BITC, it is possible that the enhanced stress caused by BITC treatment at $30^{\circ} \mathrm{C}$ may have resulted in detachment of HO-1 from the smooth ER allowing it to move throughout the cytoplasm. In A6 cells treated with BITC at $30{ }^{\circ} \mathrm{C}$, larger HO- 1 structures were also detected in $30 \%$ of cells compared to BITC at $22{ }^{\circ} \mathrm{C}$. A previous study determined that NADPH cytochrome P450 reductase promoted the oligomerization of HO-1 into larger complexes, which also contained biliverdin reductase 
(Huber et al., 2009; Linnenbaum et al., 2012). It is possible that BITC treatment at $30{ }^{\circ} \mathrm{C}$ elicited a similar oligomerization of HO-1 into higher ordered complexes. The current study also determined that treatment of A6 cells with either BITC or PEITC caused F-actin cytoskeletal disorganization.

Comparable effects on F-actin cytoskeletal structure were noted after sodium arsenite or cadmium chloride treatment of amphibian and mammalian cultured cells (Li and Chou, 1992; Gellalchew and Heikkila, 2005; Woolfson and Heikkila, 2009; Khamis and Heikkila, 2013; Khan et al., 2015). Although minimal information is available on the effect of ITCs on the F-actin cytoskeleton, it was reported that two cysteine residues conserved within all actin isoforms were vulnerable to oxidative stress (Dalle-Donne et al., 2001). Therefore, it may be possible that these two nucleophilic residues found within the actin molecule are targets for ITC modification, inducing F-actin cytoskeletal disorganization and membrane ruffling.

In this study, treatment of X. laevis A6 cells with BITC significantly enhanced the relative levels of ubiquitinated protein. Studies with HeLa cells also reported an increase in ubiquitinated protein levels after exposure to this ITC (Mi et al., 2009). BITC also inhibited the proteasome in multiple myeloma cells specifically repressing chymotrypsin-like, trypsin-like and caspase-like enzyme activities in a concentration-dependent manner (Mi et al., 2010). In this latter study, it was suggested that BITC bound directly to susceptible cysteine residues within the proteasome B3 subunit, which protrudes into the active site of the B2 subunit. It is possible that BITC treatment inhibited the proteasome of A6 cells, which resulted in the accumulation of ubiquitinated protein. BITC-induced ubiquitinated protein levels were greater in cells treated at $22{ }^{\circ} \mathrm{C}$ than at $30^{\circ} \mathrm{C}$. This finding was not unexpected given that treatment of $\mathrm{A} 6$ cells at $30^{\circ} \mathrm{C}$ alone reduced the relative level of ubiquitinated protein compared to control. Furthermore, it was possible that treatment of cells with BITC at an 
elevated temperature may have an enhanced effect on the thiols associated with cysteine residues of enzymes that function in the addition of ubiquitin to proteins targeted for degradation.

Immunocytochemical analysis employing the Proteostat aggresome detection assay determined that exposure of cells to BITC increased the levels of aggregated protein structures relative to control. Studies with mammalian cells have demonstrated the ability of BITC to not only cause proteasomal inhibition but also covalently bind and modify cysteine residues within proteins including $\alpha$ - and $\beta$ tubulin, resulting in conformational changes, exposure of hydrophobic regions and ultimately their aggregation (Mi et al., 2008; 2009; Xiao et al., 2012). Given that the tubulin family comprises 3-4\% of the total protein in eukaryotic cells, the binding of BITC to this protein alone could have accounted for a substantial portion of aggregated protein observed in A6 cells (Oakley, 2000). Other proteins that were targeted by BITC in mammalian cells include proteasomal subunits, cytochrome P450s and macrophage migration inhibitory factor (Goosen et al., 2000; Ouertatani-Sakouhi et al., 2009). In comparison to BITC, treatment of A6 cells with the proteasomal inhibitor, MG132, induced aggregated protein and the formation of numerous aggresome-like structures in the perinuclear region. This finding was in agreement with a previous study conducted in our laboratory with A6 cells as well as in mammalian cells (Ito et al., 2002; Bauer and Richter-Landsberg, 2006; Goldbaum et al., 2009; Bolhuis and Richter-Landsberg, 2010; Shen at al., 2011; Bang et al., 2014; Khan et al., 2015). These aggresome-like structures result from the coalescence of individual protein aggregates, which are then transported to the perinuclear region along microtubules employing a dynein motor (Kopito, 2000; Ito et al., 2002; Rodriguez-Gonzalez et al., 2008; Driscoll and Chowdhury, 2012; Hao et al., 2013; Richter-Landsberg and Leyk, 2013). In contrast to MG132, very few large aggregated protein structures were present in cells exposed to BITC. 
In A6 cells, immunocytochemical analysis revealed that exposure of A6 cells to BITC induced microtubule fragmentation and a decrease in cellular levels of $\alpha$-tubulin in a time-dependent manner. Disruption and degradation of the microtubule network by BITC was also observed in immunocytochemical studies conducted in mammalian tumour cells (Mi et al., 2008; 2009). It was suggested that BITC, which is a small compound, has a methyl group extending from its aromatic hydrocarbon and can easily gain access to cysteine residues buried within the tubulin molecule (Mi et al., 2008). This modification by BITC triggers tubulin conformational changes, misfolding and aggregate formation, which is then degraded by the ubiquitination-proteasome system.

Since BITC treatment decreased levels of $\alpha$-tubulin and caused the fragmentation of microtubules in A6 cells, it was possible that these phenomena blocked the movement of aggregated protein to the perinuclear region to form aggresome-like structures. This possibility was supported by the finding that pretreatment of A6 cells with BITC inhibited the accumulation of MG132-induced aggresome-like structures. It should be mentioned that factors other than microtubule fragmentation may be responsible for the lack of transport of aggregated protein in BITC-treated cells including a conformational change in dynein which is required for the movement of protein aggregates along microtubules. These results are of significance, as they not only reveal BITC's ability to induce aggregated protein but also its ability to interfere with the translocation of aggregated protein to the perinuclear region to form aggresome-like structures.

\section{Acknowledgements}

This research was supported by a Natural Sciences and Engineering Research Council (NSERC) Discovery grant (RGPIN-2014-04376) to J.J.H. During this research J.J.H. was the recipient of a 
Canada Research Chair in Stress Protein Gene Research while I.K. was the recipient of an Ontario Graduate scholarship.

\section{References}

Abdulle, R., Mohindra, A., Fernando, P., Heikkila, J.J., 2002. Xenopus small heat shock proteins, Hsp30C and Hsp30D, maintain heat- and chemically-denatured luciferase in a folding-competent state. Cell Stress Chaperones 7, 6-16.

Alam, J., Wicks, C., Stewart, D., Gong, P., Touchard, C., Otterbein, S., Choi, A.M.K., Burow, M.E., Tou, J., 2000. Mechanism of heme oxygenase-1 gene activation by cadmium in MCF-7 mammary epithelial cells: role of p38 kinase and Nrf2 transcription factor. J. Biol. Chem. 275, 27694-27702.

An, H., Statsyuk, A., 2015. An inhibitor of ubiquitin conjugation and aggresome formation. Chem. Sci. 6, 5235-5245.

Bang, Y., Kang, B.Y., Choi, H.J., 2014. Preconditioning stimulus of proteasome inhibitor enhances aggresome formation and autophagy in differentiated SH-SY5Y cells. Neurosci. Lett. 566, 263268.

Bolhuis, S., Richter-Landsberg, C., 2010. Effect of proteasome inhibition by MG-132 on HSP27 oligomerization, phosphorylation, and aggresome formation in the OLN-93 oligodendroglia cell line. J. Neurochem. 114, 960-971.

Brunt, J.J., Khan, S., Heikkila, J.J., 2011. Sodium arsenite and cadmium chloride induction of proteasome inhibition and HSP accumulation in Xenopus laevis A6 kidney epithelial cells. Comp. Biochem. Physiol. C Toxicol. Pharmacol. 155, 307-317.

Chau, L.Y., 2015. Heme oxygenase-1: emerging target of cancer therapy. J. Biomed. Sci. doi: 10.1186/s12929-015-0128-0.

Choi, R.J., Cheng, M.S., Shik, K.Y., 2014. Desoxyrhapontigenin up-regulates Nrf2-mediated heme oxygenase-1 expression in macrophages and inflammatory lung injury. Redox Biol. 18, 504-512.

Converso, D.P., Taillé, C., Carreras, M.C., Jaitovich, A. Poderoso, J.J., Boczkowski, J., 2006. HO-1 is located in liver mitochondria and modulates mitochondrial heme content and metabolism.

FASEB J. 20, 1236-1238.

Correa-Costa, M., Amano, M.T, Camara, N.O., 2012. Cytoprotection behind heme oxygenase-1 in renal diseases. World J. Nephrol. 1, 4-11. 
Dalle-Donne, I., Rossi, R., Milzani, A., Di Simplicio, P., Colombo, R., 2001. The actin cytoskeleton response to oxidants: from small heat shock protein phosphorylation to changes in the redox state of actin itself. Free Radic. Biol. Med. 31, 1624-1632.

Del Razo, L.M., Quintanilla-Vega, B., Brambila-Colombres, E., Calderon-Aranda, E.S., Manno, M., Albores, A., 2001. Stress proteins induced by arsenic. Toxicol. Appl. Pharmacol. 177, 132-148.

Driscoll, J.J., Chowdhury, R.D., 2012. Molecular crosstalk between the proteasome, aggresomes and autophagy: translational potential and clinical implications. Cancer Lett. 325, 147-154.

Dufour, V., Stahl, M., Rosenfeld, E., Stintzi, A., Baysse, C., 2013. Insights into the mode of action of benzyl isothiocyanate on Campylobacter jejuni. Appl. Environ. Microbiol. 79, 6958-6968.

Elicker, K.S., Hutson, L.D., 2007. Genome-wide analysis and expression profiling of the small heat shock proteins in zebrafish. Gene 403, 60-69.

Fernando, P., Heikkila, J.J., 2000. Functional characterization of Xenopus small heat shock protein, Hsp30C: The carboxyl end is required for stability and chaperone activity. Cell Stress Chaperones 5, 148-159.

Fernando, P., Abdulle, R., Mohindra, A., Guillemette, J.G., Heikkila, J.J., 2002. Mutation or deletion of the C-terminal tail affects the function and structure of Xenopus laevis small heat shock protein, hsp30. Comp. Biochem. Physiol. B Biochem. Mol. Bol. 133, 95-103.

Fernando, P., Megeny, L.A., Heikkila, J.J., 2003. Phosphorylation-dependent structural alterations in the small hsp30 chaperone are associated with cellular recovery. Exp. Cell Res. 286, 175-185.

Galazyn-Sidorczuk, M., Brzoska, M.M., Jurczuk, M., Moniuszko-Jakoniuk, J., 2009. Oxidative damage to proteins and DNA in rats exposed to cadmium and/or ethanol. Chem. Biol. Interac. 180, 31-38.

Gandini, N.A., Fermento, M.E., Salomón, D.G., Blasco, J., Patel, V., Gutkind, J.S., Molinolo, A.A., Facchinetti, M.M., Curino, A.C., 2012. Nuclear localization of heme oxygenase-1 is associated with tumor progression of head and neck squamous cell carcinomas. Exp. Mol. Pathol. 93, 237245.

Gauley, J., Young, J.T.F., Heikkila, J.J., 2008. Intracellular localization of the heat shock protein, HSP110, in Xenopus laevis A6 kidney epithelial cells. Comp. Biochem. Physiol. A Mol. Integr. Physiol. 151, 133-138.

Gellalchew, M., Heikkila, J.J., 2005. Intracellular localization of Xenopus small heat shock protein, hsp30, in A6 kidney epithelial cells. Cell Biol. Int. 29, 221-227.

Giacoppo, S., Galuppo, M., Monttaut, S., Iori, R., Rollin, P., Bramanti, P., Mazzon, E., 2015. An overview on neuroprotective effects of isothiocyanates for the treatment of neurodegenerative diseases. Fitoterapia 106, 12-21. 
Goldbaum, O., Riedel, M., Stahnke, T., Richter-Landsberg, C., 2009. The small heat shock protein HSP25 protects astrocytes against stress induced by proteasomal inhibition. Glia 57, 1566-1577.

Goosen, T.C., Kent, U.M., Brand, L., Hollenberg, P.F., 2000. Inactivation of cytochrome P450 2 B1 by benzyl isothiocyanate, a chemopreventative agent from cruciferous vegetables. Chem. Res. Toxicol. 13, 1349-1359.

Gozzelino, R., Jeney, V., Soares, M.P., 2010. Mechanisms of cell protection by heme oxygenase-1. Annu. Rev. Pharmacol. Toxicol. 50, 323-354.

Hao, R., Nanduri, P., Rao, Y., Panichelli, R.S., Ito, A., Yoshida, M., Yaho, T.-P., 2013. Proteasomes activate aggresome disassembly and clearance by producing unanchored ubiquitin chains. Mol. Cell. 51, 819-828.

Heikkila, J.J., 2010. Heat shock protein gene expression and function in amphibian model systems. Comp. Biochem. Physiol. A Mol. Integr. Physiol. 156, 19-33.

Heikkila, J.J., 2017. The expression and function of hsp30-like small heat shock protein genes in amphibians, birds, fish, and reptiles. Comp. Biochem. Physiol. A Mol. Integr. Physiol. 203, 179192.

Helbing, C., Gallimore, C., Atkinson, B.G., 1996. Characterization of a Rana catesbeiana hsp30 gene and its expression in the liver of this amphibian during both spontaneous and thyroid hormoneinduced metamorphosis. Dev. Genet. 18, 223-233.

Huber, III, W.J. Scruggs, B.A., Backes, W.L., 2009. C-terminal membrane spanning region of human heme oxygenase-1 mediates a time-dependent complex formation with cytochrome P450 reductase. Biochemistry 48, 190-197.

Ito, H., Kamei, K., Iwamoto, I., Inaguma, Y., Garcia-Mata, R., Sztul, E., Kato, K., 2002. Inhibition of the proteasome induces accumulation, phosphorylation, and recruitment of HSP27 and alphaßcrystallin to aggresomes. J. Biochem. 131, 593-603.

Katoh, Y., Fujimoto, M., Nakamura, K., Inouye, S., Sugahara, K., Izu, H., Nakai, A., 2004. Hsp25, a member of the Hsp30 family, promotes inclusion formation in response to stress. FEBS Lett. $565,28-32$.

Khamis, I., Heikkila, J.J., 2013. Enhanced HSP30 and HSP70 accumulation in Xenopus cells subjected to concurrent sodium arsenite and cadmium chloride stress. Comp. Biochem. Physiol. C Toxicol. Pharmacol. 158, 165-172.

Khan, S., Heikkila, J.J., 2011. Curcumin-induced inhibition of proteasomal activity, enhanced HSP accumulation and the acquisition of thermotolerance in Xenopus laevis A6 cells. Comp. Biochem. Physiol. A Mol. Integr. Physiol. 158, 566-576.

Khan, S., Heikkila, J.J., 2014. Distinct patterns of HSPS30 and HSP70 degradation in Xenopus laevis A6 cells recovering from thermal stress. Comp. Biochem. Physiol. A Mol. Integr. Physiol. 168, 1-10. 
Khan, S., Khamis, I., Heikkila, J.J., 2015. The small heat shock protein, HSP30, is associated with aggresome-like inclusion bodies in proteasomal inhibitor-, arsenite-, and cadmium-treated Xenopus kidney cells. Comp. Biochem. Physiol. A Mol. Integr. Physiol. 189, 30-40.

Kobayashi, A., Kang, M.I., Okawa, H., Ohtsuji, M., Zenke, Y., Chiba, T., Igarashi, K., Yamamoto, M., 2004. Oxidative stress sensor Keap1 functions as an adaptor for Cul3-based E3 ligase to regulate proteasomal degradation of Nrf2. Mol. Cell Biol. 24, 7130-7139.

Kopito, R.R., 2000. Aggresomes, inclusion bodies and protein aggregation. Trends Cell Biol. 10, 524530.

Li, Y., Karagoz, G.E., Seo, Y.H., Zhang, T., Jiang, Y., Yu, Y., Duarte, A.M., Schwartz, S.J., Boelens, R., Carroll, K., Rudiger, S.G., Sun, D., 2012. Sulforaphane inhibits pancreatic cancer through disrupting Hsp90-p50 (Cdc37) complex and direct interactions with amino acids residues of Hsp90. J. Nutr. Biochem. 23, 1617-1626.

Li, W., Chou, I.N., 1992. Effects of sodium arsenite on the cytoskeleton and cellular glutathione levels in cultured cells. Toxicol. Appl. Pharmacol. 114, 132-139.

Lin, Q., Weis, S., Yang, G., Weng, Y.H., Helston, R., Rish, K., Smith, A., Bordner, J., Polte, T., Gaunitz, F., Dennery, P.A., 2007. Heme oxygenase-1 protein localizes to the nucleus and activates transcription factors important in oxidative stress. J. Biol. Chem. 282, 20621-20633.

Liu, J., Kadiiska, M.B., Liu, Y., Lu, T., Qu, W., Waalkes, M.P., 2001. Stress-related gene expression in mice treated with inorganic arsenicals. Toxicol. Sci. 61, 314-320.

Linnenbaum, M., Busker, M., Kraehling, J.R., Behrends, S., 2012. Heme oxygenase isoforms differ in their subcellular trafficking during hypoxia and are differentially modulated by cytochrome P450 reductase. PLoS One 7, e35483. doi: 10.1371/journal.pone.0035483.

Manwell, L.A., Heikkila, J.J. 2007. Examination of KNK437- and quercitin-mediated inhibition of heat shock-induced heat shock protein gene expression in Xenopus laevis cultured cells. Comp. Biochem. Physiol. A Mol. Integr. Physiol. 148, 521-530.

Martin, D., Rojo, A.I., Salinas, M., Diaz, R., Gallardo, G., Alam, J., Ruiz de Galarreta, C.M., Cuadrado, A., 2004. Regulation of heme oxygenase-1 expression through the phosphatidylinositol 3-kinase/Akt pathway and the Nrf2 transcription factor in response to the antioxidant phytochemical carnosol. J. Biol. Chem. 279, 8919-8929.

Mi, L., Wang, X., Govind, S., Hood, B.L., Veenstra, T.D., Conrads, T.P., Saha, D.T., Goldman, R., Chung, F.L., 2007. The role of protein binding in induction of apoptosis by phenethyl isothiocyanate and sulforaphane in human non-small lung cancer cells. Cancer Res. 67, 64096416.

Mi, L., Xiao, Z., Hood, B.L., Dakshanamurthy, S., Wang, X., Govind, S., Conrads, T.P., Veenstra, T.D., Chung, F.L., 2008. Covalent binding to tubulin by isothiocyanates. A mechanism of cell growth arrest and apoptosis. J. Biol. Chem. 283, 22136-22146. 
Mi, L., Gan, N., Cheema, A., Dakshanamurthy, S., Wang, X., Yang, D.C., Chung, F.L., 2009. Cancer preventive isothiocyanates induce selective degradation of cellular alpha- and beta-tubulins by proteasomes. J. Biol. Chem. 284, 17039-17051.

Mi, L., Gan, N., Chung, F.L., 2010. Isothiocyanates inhibit proteasome activity and proliferation of multiple myeloma cells. Carcinogenesis 32, 216-223.

Mi, L., Di Pasqua, A.J., Chung, F.L., 2011. Proteins as binding targets of isothiocyanates in cancer prevention. Carcinogenesis 32, 1405-1413.

Molina-Vargas, L.F., 2013. Mechanism of action of isothiocyanates. A review. Agron. Colomb. $31,1$.

Morimoto, R.I., 1998. Regulation of the heat shock transcriptional response: Cross talk between a family of heat shock factors, molecular chaperones, and negative regulators. Genes Dev. 12, 3788-3796.

Morimoto, R.I., 2008. Proteotoxic stress and inducible chaperone networks in neurodegenerative disease and aging. Genes Dev. 22, 1427-1438.

Morris, M.E., Dave, R.A., 2014. Pharmacokinetics and pharmacodynamics of phenethyl isothiocyanate: implications in breast cancer prevention. AAPS J. 16, 705-713.

Mulligan-Tuttle, A., Heikkila, J.J., 2007. Expression of the small heat shock protein gene, hsp30, in Rana catesbeiana fibroblasts. Comp. Biochem. Physiol. A Mol. Integr. Physiol. 148, 308-316.

Music, E., Khan, S., Khamis, I., Heikkila, J.J., 2014. Accumulation of heme oxygenase-1 (HSP32) in Xenopus laevis A6 kidney epithelial cells treated with sodium arsenite, cadmium chloride or proteasomal inhibitors. Comp. Biochem. Physiol. C Toxicol. Pharmacol. 166, 75-87.

Naidu, S.D., Sutherland, C., Zhang, Y., Risco, A., de la Vega, L., Caunt, C.J., Hastie, C.J., Lamont, D.J., Torrente, L., Chowdhry, S., Benjamin, I.J., Keyse, S.M., Cuenda, A., Dinkova-Kostova, A.T., 2016. Heat Shock Factor 1 Is a Substrate for p38 Mitogen-Activated Protein Kinases. Mol. Cell Biol. 36, 2403-2417.

Namba, F., Go, H., Murphy, J.A., La, P., Yang, G., Sengupta, S., Fernando, A.P., Yohannes, M., Biswas, C., Wehrli, S.L., Dennery, P.A., 2014. Expression level and subcellular localization of heme oxygenase-1 modulates its cytoprotective properties in response to lung injury: a mouse model. PLoS One doi: 10.1371/journal.pone.0090936.

Norris, C.E., Brown, M.A., Hickey, E., Weber, L.A., Hightower, L.E., 1997. Low-molecular weight heat shock proteins in a desert fish (Poeciliopsis lucida): homologs of human Hsp27 and Xenopus Hsp30. Mol. Biol. Evol. 14, 115-129.

Oakley, B.R., 2000. An abundance of tubulins. Trends Cell Biol. 10, 537-542.

Ohan, N.W., Tam, Y., Fernando, P., Heikkila, J.J., 1998. Characterization of a novel group of basic small heat shock proteins in Xenopus laevis A6 kidney epithelial cells. Biochem. Cell Biol. 76, 665-671. 
Ouertatani-Sakouhi, H., El-Turk, F., Fauvet, B., Roger, T., Le Roy, D., Karpinar, D.P., Leng, L., Bucala, R., Zweckstetter, M., Calandra, T., Lashuel, H.A., 2009. A new class of isothiocyanatebased irreversible inhibitors of Macrophage Migration Inhibitory Factor (MIF). Biochemistry 48, 9858-9870.

Prawan, A., Keum, Y.S., Khor, T.O., Yu, S., Nair, S., Li, W., Hu, L., Kong, An.T., 2007. Structural influence of isothiocyanates on the antioxidant response element (ARE)-mediated heme oxygenase-1 (HO-1) expression. Pharm. Res. 25, 836-844.

Richter-Landsberg, C., Leyk, J., 2013. Inclusion body formation, macroautophagy, and the role of HDAC6 in neurodegeneration. Acta. Neuropath. 126, 793-807.

Rodriguez-Gonzalez, A., Lin, T., Ikeda, A.K., Simms-Waldrip, T., Fu, C., Sakamoto, K.M., 2008. Role of the aggresome pathway in cancer: targeting histone deacetylase 6-dependent protein degradation. Cancer Res. 68, 2557-2560.

Ryter, S., Kvam, E., Tyrrell, R.M., 1999. Heme oxygenase activity determination by high performance liquid chromatography. Methods Enzymol. 300, 322-336.

Ryter, S.W., Alam, J., Choi, A.M., 2006. Heme oxygenase-1/carbon monoxide: from basic science to therapeutic applications. Physiol. Rev. 86, 583-650.

Samuel, S., Kathirvel, R., Jayavelu, T., Chinnakkannu, P., 2005 Protein oxidative damage in arsenic induced rat brain: influence of DL--lipoic acid. Toxicol. Lett. 155, 27-34.

Sarkars, R., Mukherjee, S., Roy, M., 2013. Targeting heat shock proteins by phenethyl isothiocyanate results in cell-cycle arrest and apoptosis of human breast cancer cells. Nutr. Cancer. 65, 480-493.

Shen, D., Coleman, J., Chan, E., Nicholson, T.P., Sheppard, P.W., Patton, W.F., 2011. Novel celland tissue-based assays for detecting misfolded and aggregated protein accumulation within aggresomes and inclusion bodies. Cell Biochem. Biophys. 60, 173-185.

Shirriff, C.S., Heikkila, J.J., 2017. Characterization of cadmium chloride-induced BiP accumulation in Xenopus laevis A6 kidney epithelial cells. Comp. Biochem. Physiol. C Toxicol. Pharmacol. 191, 117-128.

Slebos, D.J., Ryter, S.W., van der Toorn, M., Liu, F., Guo, F., Baty, C.J., Karlsson, J.M., Watkins, S.C., Kim, H.P., Wang, X., Lee. J.S., Postma, D.S., Kauffman, H.F., Choi, A.M., 2007. Mitochondrial localization and function of heme oxygenase-1 in cigarette smoke-induced cell death. Am. J. Respir. Cell. Mol. Biol. 36, 409-417.

Stewart, D., Killeen, E., Naquin, R., Alam, S., Alam, J., 2003. Degradation of transcription factor $\mathrm{Nrf} 2$ via the ubiquitin-proteasome pathway and stabilization by cadmium. J. Biol. Chem. 78, 2396-2302.

Suzuki, H., Tashiro, S., Sun, J., Doi, H., Satomi, S., Igarashi, K., 2003. Cadmium induces nuclear export of Bach1, a transcriptional repressor of heme oxygenase-1 gene. J. Biol. Chem. 278, 49246-49253. 
Tenhunen, R., Marver, H.S., Schmid, R., 1968. The enzymatic conversion of heme to bilirubin by microsomal heme oxygenase. Proc. Natl. Acad. Sci. USA. 61, 748-755.

Uversky, V.N., Fink, A., 2007. Protein misfolding, aggregation, and conformational diseases. Molecular Mechanisms of Conformational Diseases 6, 61-110.

Verghese, J., Abrams, J., Wang, Y., Morano, K.A., 2012. Biology of the heat shock response and protein chapers: budding yeast (Saccharomyces cerevisiae) as a model system. Microbiol. Mol. Biol. Rev. 76, 115-158.

Waisberg, M., Pius, J., Hale, B., Beyersmann, D., 2003. Molecular and cellular mechanisms of cadmium carcinogenesis. Toxicology 192, 95-117.

Walcott, S.E., Heikkila, J.J., 2010. Celastrol can inhibit proteasome activity and upregulate the expression of heat shock protein genes, hsp30 and hsp70, in Xenopus laevis A6 cells. Comp. Biochem. Physiol. A Mol. Integr. Physiol. 156, 285-293.

Wang, Y., Gu, Y., Qin, G., Zhong, L., Meng, Y., 2013. Curcumin ameliorates the permability of the blood-brain barrier during hypoxia by upregulating heme oxygenase-1 expression in brain microvascular endothelial cells. J. Mol. Neurosci. 51, 344-351.

Woolfson, J.P., Heikkila, J.J., 2009. Examination of cadmium-induced expression of the small heat shock protein gene, hsp30, in Xenopus laevis A6 kidney epithelial cells. Comp. Biochem. Physiol. A Mol. Integr. Physiol. 152, 91-99.

Wu, W.T., Chi, K.H., Ho, F.M., Tsao, W.C., Lin, W.W., 2004. Proteasome inhibitors up-regulate heme oxygenase-1 gene expression: requirement of p38 MAPK (mitogen-activated protein kinase) activation but not of NF-kappaB (nuclear factor kappaB) inhibition. Biochem. J. 379, 587-593.

Xiao, Z., Mi, L., Chung, F-.L., Veenstra, T.D., 2012. Proteomic Analysis of Covalent Modifications of Tubulins by Isothiocyanates. J. Nutr. 142, 1377-1381.

Xie, J., Tang, L., Lu, L., Zhang, L., Xi, L., Liu, H.C., Odle, J., Luo, X., 2014. Differential expression of heat shock transcription factors and heat shock proteins after acute and chronic heat stress in laying chickens (Gallus gallus). PLoS One doi: 0.1371/journal.pone.0102204.

Xiong, R., Siegel, D., Ross, D., 2013. The activation sequence of cellular protein handling systems after proteasomal inhibition in dopaminergic cells. Chem. Biol. Interact. 204, 116-124.

Xu, C., Yuan, X., Pan, Z., Shen, G., Kim, J.H., Yu, S., Khor, T.O., Li, W., Ma, J., Kong, A.N., 2006. Mechanism of action of isothiocyanates: the induction of ARE-regulated genes is associated with activation of ERK and JNK and the phosphorylation and nuclear translocation of Nrf2. Mol. Cancer Ther. 5, 1918-1926.

Yachie, A., Niida, Y., Wada, T., Igarashi, N., Kaneda, H., Toma, T., Ohta, K., Kasahara, Y., Koizumi, S., 1999. Oxidative stress causes enhanced endothelial cell injury in human heme oxygenase-1 deficiency. J. Clin. Invest. 103, 129-135. 
Yamamoto, N., Izumi, Y., Matsuo, T., Wakita, S., Kume, T., Takada-Takatori, Y., Sawada, H., Akaike, A., 2010. Elevation of heme oxygenase-1 by proteasome inhibition affords dopaminergic neuroprotection. J. Neurosci. Res. 88, 1934-1942.

Young, J.T.F., Gauley, J., Heikkila, J.J., 2009. Simultaneous exposure of Xenopus A6 kidney epithelial cells to concurrent mild sodium arsenite and heat stress results in enhanced $h s p 30$ and hsp70 gene expression and the acquisition of thermotolerance. Comp. Biochem. Physiol. A Mol. Integr. Physiol. 153, 417-424.

Young, J.T.F., Heikkila, J.J., 2010. Proteasome inhibition induces $h s p 30$ and $h s p 70$ gene expression as well as the acquisition of thermotolerance in Xenopus laevis A6 cells. Cell Stress Chaperones $15,323-334$.

Zaarur, N., Meriin, A.B., Gabai, V.L., Sherman, M.Y., 2008. Triggering aggresome formation. Dissecting aggresome-targeting and aggregation signals in synphilin 1. J. Biol. Chem. 283, 27575-27584.

Zhang, R., Loganathan, S., Humphreys, I., Srivastava, S.K., 2006. Benzyl isothiocyanate-induced DNA damage causes $\mathrm{G}_{2} / \mathrm{M}$ cell cycle arrest and apoptosis in human pancreatic cancer cells. J. Nutr. 136, 2728-2734.

\section{Figure legends:}

Figure 1. Relative levels of HO-1, HSP70 and HSP30 in cells subjected to BITC treatment at 22 or 30 ${ }^{\circ} \mathrm{C}$. A6 cells were maintained at $22{ }^{\circ} \mathrm{C}(\mathrm{C})$ or exposed to either $5,7.5$ or $10 \mu \mathrm{M}$ BITC at 22 or $30{ }^{\circ} \mathrm{C}$ for $12 \mathrm{~h}$. Additionally, cells were exposed to a temperature of $30{ }^{\circ} \mathrm{C}$ for $12 \mathrm{~h}$ or treated with $30 \mu \mathrm{M}$ MG132 (MG; inducer of HO-1, HSP70 and HSP30 accumulation in A6 cells) for $12 \mathrm{~h}$ at $22^{\circ} \mathrm{C}$. A) Total protein was isolated and subjected to immunoblot analysis using an anti-HO-1, anti-HSP70, antiHSP30 or anti-actin antibody as described in Materials and methods. This panel displays a representative immunoblot. B) ImageJ software was used to perform densitometric analysis of signals obtained for HO-1, HSP70 and HSP30 as described in Materials and methods. The data were expressed as a percentage of the maximum band density obtained for each protein $(5 \mu \mathrm{M}$ BITC at 22 ${ }^{\circ} \mathrm{C}$ for $\mathrm{HO}-1 ; 10 \mu \mathrm{M}$ at $30{ }^{\circ} \mathrm{C}$ for $\mathrm{HSP} 70 ; 7.5 \mu \mathrm{M}$ at $30{ }^{\circ} \mathrm{C}$ for HSP30), while standard errors were 
indicated with vertical bars. A one-way ANOVA with a Tukey's Multiple Comparisons post-test was used to determine significance. Significant differences between the control cells and treated cells are indicated with an asterisk $(p<0.05)$. These data are representative of 4 separate experiments.

Figure 2. Representative immunoblot showing the effect of PEITC on HO-1, HSP70 and HSP30 accumulation at 22 or $30^{\circ} \mathrm{C}$. A) Cells were incubated with 5 or $7.5 \mu \mathrm{M}$ PEITC at 22 or $30^{\circ} \mathrm{C}$ for $12 \mathrm{~h}$. Some A6 cell cultures were maintained at $22{ }^{\circ} \mathrm{C}(\mathrm{C})$, exposed to a temperature of $30^{\circ} \mathrm{C}$ for $12 \mathrm{~h}$, or treated with $30 \mu \mathrm{M} \mathrm{MG132}(\mathrm{MG})$ for $12 \mathrm{~h}$ at $22^{\circ} \mathrm{C}$. Following the treatments, total protein was isolated and subjected to immunoblot analysis using an anti-HO-1, anti-HSP70, anti-HSP30 or antiactin antibody. B) Densitometric analysis of the band densities obtained for HO-1 and HSP70 utilized ImageJ software. The data were expressed as a percentage of the maximum band density obtained for either HO-1 or HSP70 (5 $\mu \mathrm{M}$ PEITC at $22{ }^{\circ} \mathrm{C}$ for both), while the standard errors were represented by vertical bars. Densitometry was not carried out with HSP30 immunoblots since the relative levels induced by PEITC were very low or undetectable. Statistical analysis was performed and the significant differences were indicated with an asterisk $(\mathrm{p}<0.05)$. These data are representative of 3 separate experiments.

Figure 3. Effect of BITC on the localization of HO-1 in A6 cells. Cells were cultured on glass coverslips and then maintained at $22{ }^{\circ} \mathrm{C}(\mathrm{C})$ or incubated at $30{ }^{\circ} \mathrm{C}$ for $12 \mathrm{~h}$. Other cells were treated with $7.5 \mu \mathrm{M}$ of BITC for $12 \mathrm{~h}$ at 22 or $30^{\circ} \mathrm{C}$. HO- 1 was detected with a rabbit anti-HO-1 antibody, and a secondary antibody conjugated to Alexa-488 (green). F-actin and nuclei were stained with phalloidin conjugated to TRITC (red) or with DAPI (blue), respectively. The columns, from left to right, show the fluorescence detection channels for F-actin, HO-1, and merged images, which also includes DAPI staining. Yellow arrows indicate membrane ruffling or disorganization of the F-actin cytoskeleton. White arrows indicate larger HO-1 staining structures. The $20 \mu \mathrm{m}$ scale bars are 
indicated at the bottom right corner of each panel. These results are representative of 3 different experiments.

Figure 4. Effect of PEITC on the localization of HO-1 in A6 cells. Cells were cultured on glass coverslips and then maintained at $22{ }^{\circ} \mathrm{C}(\mathrm{C})$ or incubated at $30{ }^{\circ} \mathrm{C}$ for $12 \mathrm{~h}$. Other cells were treated with $5 \mu \mathrm{M}$ of PEITC for $12 \mathrm{~h}$ at 22 or $30{ }^{\circ} \mathrm{C}$. HO- 1 was detected with a rabbit anti-HO-1 antibody, and a secondary antibody conjugated to Alexa-488 (green). F-actin was stained with phalloidin conjugated to TRITC (red) while nuclei were visualized using DAPI (blue). The columns from left to right show the fluorescence detection channels for F-actin, HO-1, and merged images, which also includes DAPI staining. Yellow arrows indicate membrane ruffling or disorganization of the F-actin cytoskeleton. The $20 \mu \mathrm{m}$ scale bars are indicated at the bottom right corner of each panel. These results are representative of 3 different experiments.

Figure 5. Effect of BITC on ubiquitinated protein levels. A) Cells were maintained at $22{ }^{\circ} \mathrm{C}(\mathrm{C})$, incubated at $30^{\circ} \mathrm{C}$, or exposed to $7.5 \mu \mathrm{M}$ BITC at 22 or $30^{\circ} \mathrm{C}$ for $12 \mathrm{~h}$. After the treatments, total protein was isolated and subjected to immunoblot analysis utilizing an anti-ubiquitin antibody, with a representative immunoblot shown. The positions of molecular mass standards in $\mathrm{kDa}$ are shown in the first lane. A section of a representative Ponceau S stained membrane is shown below. B) Densitometric analysis of the band intensity utilized ImageJ software, and the data is expressed relative to control levels. The standard error is represented by vertical error bars. Statistical analysis was performed and the significant differences are indicated with an asterisk $(\mathrm{p}<0.05)$ or a triangle $(\mathrm{p}<0.1)$. These data are representative of 4 separate experiments.

Figure 6. Examination of aggregated protein and HSP30 localization in A6 cells treated with BITC. Cells were grown on glass coverslips and maintained at $22{ }^{\circ} \mathrm{C}$ or exposed to $7.5 \mu \mathrm{M}$ BITC at $22{ }^{\circ} \mathrm{C}$ for 
$12 \mathrm{~h}$. Some cells were treated with $30 \mu \mathrm{M}$ MG132 (MG) for $12 \mathrm{~h}$ at $22^{\circ} \mathrm{C}$. The Proteostat aggresome detection kit was used to directly stain aggregated protein and aggresomes (red) while nuclei were stained directly with DAPI (blue). HSP30 was detected with a rabbit anti-HSP30 antibody and a secondary antibody conjugated to Alexa-488 (green). From left to right, the columns display fluorescence detection channels for the Proteostat dye, HSP30 and merger of ProteoStat dye, HSP30 and DAPI. In MG-treated cells, white arrows indicate a large number of aggresome-like structures that co-localize with large HSP30 staining structures in the perinuclear region. The $20 \mu \mathrm{m}$ scale bars are indicated at the bottom right corner of each panel. These results are representative of 3 different experiments.

Figure 7. Time course examining the effect of BITC treatment on actin and microtubule cytoskeletal structure. Cells were cultured on glass coverslips and then maintained at $22{ }^{\circ} \mathrm{C}(\mathrm{C})$ or treated with 7.5 $\mu \mathrm{M}$ BITC at $22{ }^{\circ} \mathrm{C}$ for 4,8 or $12 \mathrm{~h}$. $\alpha$-tubulin was detected with a mouse anti- $\alpha$-tubulin antibody and a secondary antibody conjugated to Alexa-488 (green). Actin and nuclei staining utilized phalloidin conjugated to TRITC (red) and DAPI (blue), respectively. The columns, from left to right, show the fluorescence detection channels for actin, $\alpha$-tubulin, and merged images plus DAPI staining. Yellow arrows indicate collapse or disorganization of the F-actin cytoskeleton while white arrows indicate the presence of microtubule fragmentation. White asterisks indicate the presence of a cell with a collapsed F-actin cytoskeleton. The $20 \mu \mathrm{m}$ scale bars are indicated at the bottom right corner of each panel. These images are representative of 3 different experiments.

Figure 8. Effect of BITC on $\alpha$-tubulin and HO-1 levels in A6 cells. Cells were maintained at $22{ }^{\circ} \mathrm{C}(\mathrm{C})$, or treated with $7.5 \mu \mathrm{M}$ BITC for 4,8 or $12 \mathrm{~h}$ at $22{ }^{\circ} \mathrm{C}$. A) Total protein was isolated and subjected to immunoblot analysis using an anti- $\alpha$-tubulin, anti-HO-1 or anti-actin antibody as described in Materials and methods, with a representative immunoblot shown. B) Image $\mathbf{J}$ software was used to perform 
densitometric analysis on the signal intensity for $\alpha$-tubulin and HO-1. The data are expressed as a percentage of control levels for $\alpha$-tubulin or as a percentage of the maximum signal for HO-1 (12 h). The standard error is represented by vertical bars. Statistical analysis was performed as described in Materials and methods, and significant differences are indicated with an asterisk $(\mathrm{p}<0.05)$. These results are representative of 3 different experiments.

Figure 9. Effect of BITC pretreatment on the formation of MG132-induced aggresome-like structures in A6 cells. A6 cells were cultured on glass coverslips and then maintained at $22{ }^{\circ} \mathrm{C}(\mathrm{C})$ or incubated with $30 \mu \mathrm{M}$ MG132 (MG) for $12 \mathrm{~h}$. Other cells were pretreated with $7.5 \mu \mathrm{M}$ BITC for 2 or $4 \mathrm{~h}$ at $22^{\circ} \mathrm{C}$ before exposure to $30 \mu \mathrm{M}$ MG132 for $12 \mathrm{~h}$ at $22^{\circ} \mathrm{C}$. $\alpha$-tubulin was detected with a mouse anti- $\alpha$ tubulin antibody and a secondary antibody conjugated to Alexa-488 (green). The Proteostat aggresome detection kit was used to stain aggregated protein and aggresome-like structures. White arrows indicate microtubule fragmentation, while green arrows denote aggresome-like structures in the perinuclear region. The $20 \mu \mathrm{m}$ scale bars are indicated at the bottom right corner of each panel. These images are representative of 3 different experiments. 
Fig. 1 Khamis \& Heikkila
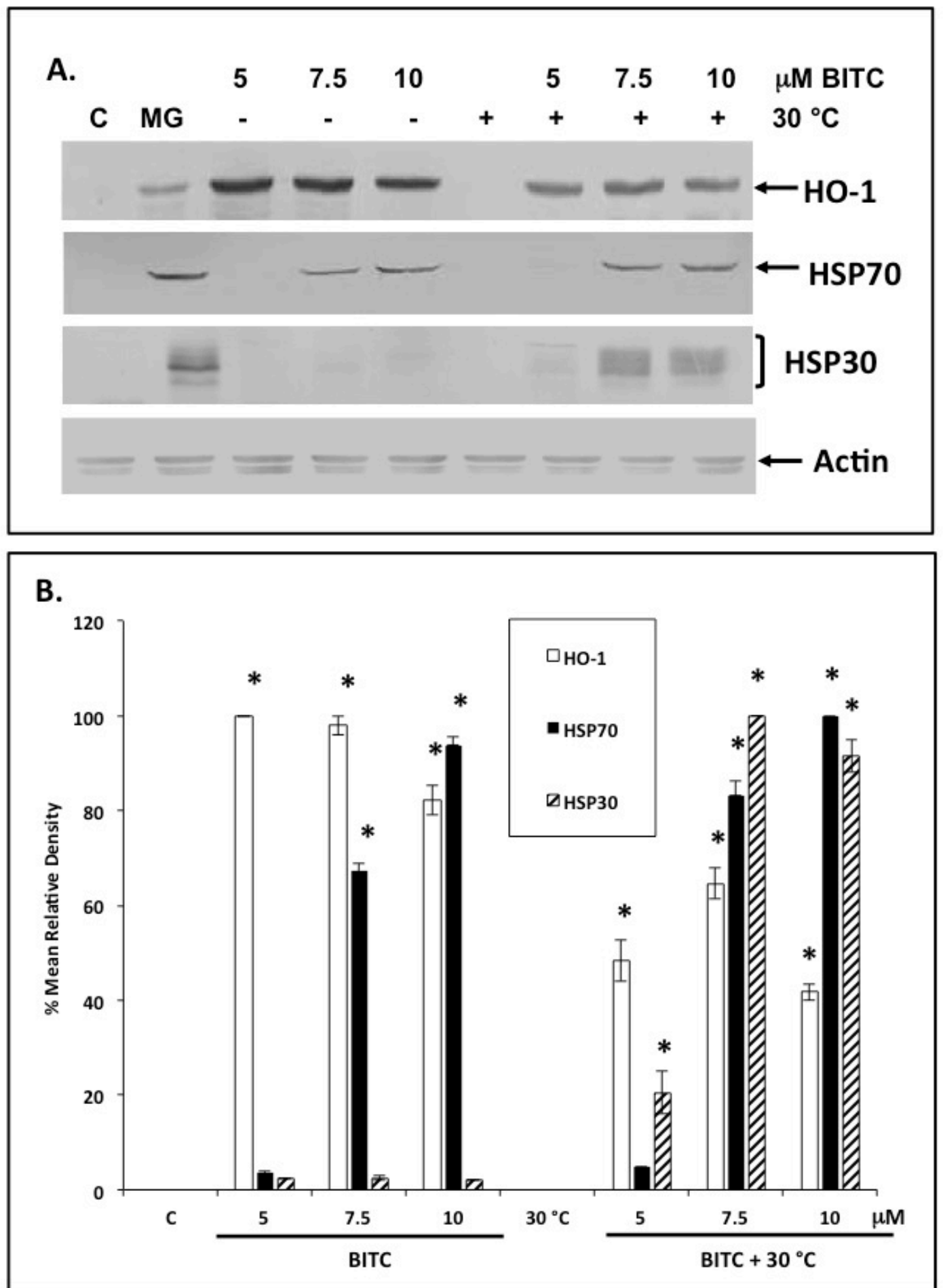
Fig. 2 Khamis \& Heikkila
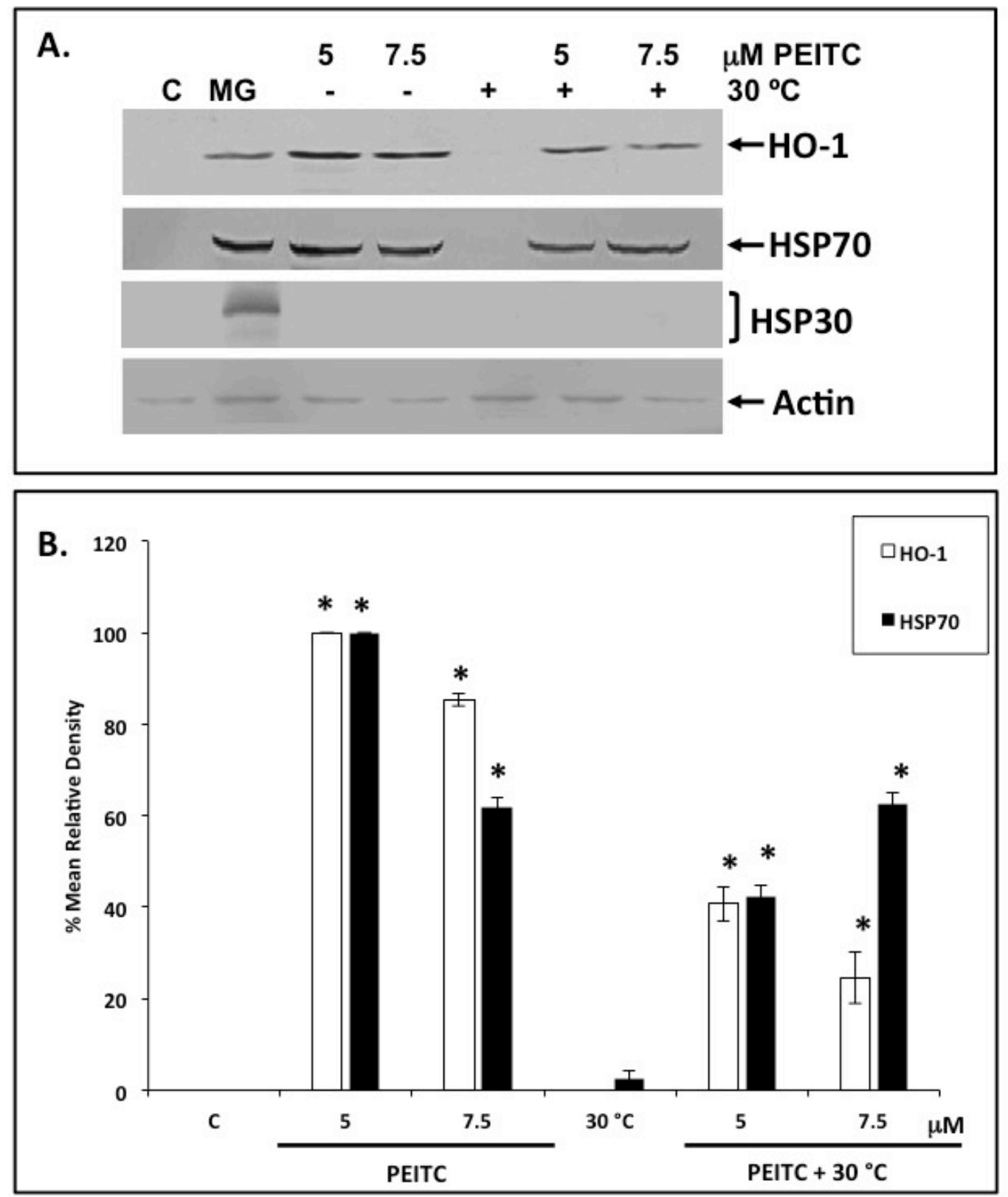
Fig. 3 Khamis \& Heikkila

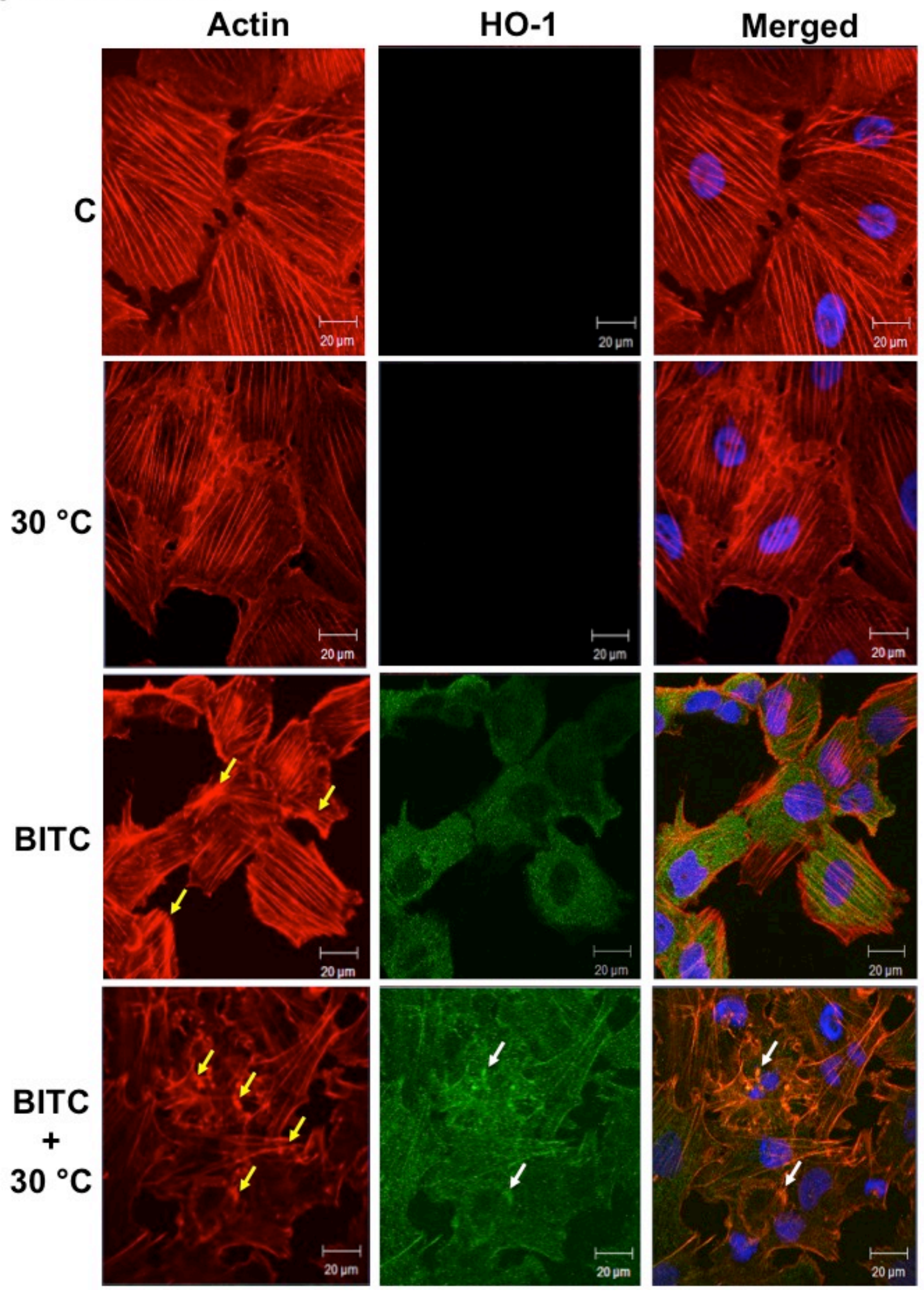


Fig. 4 Khamis \& Heikkila

Actin

HO-1

Merged

C
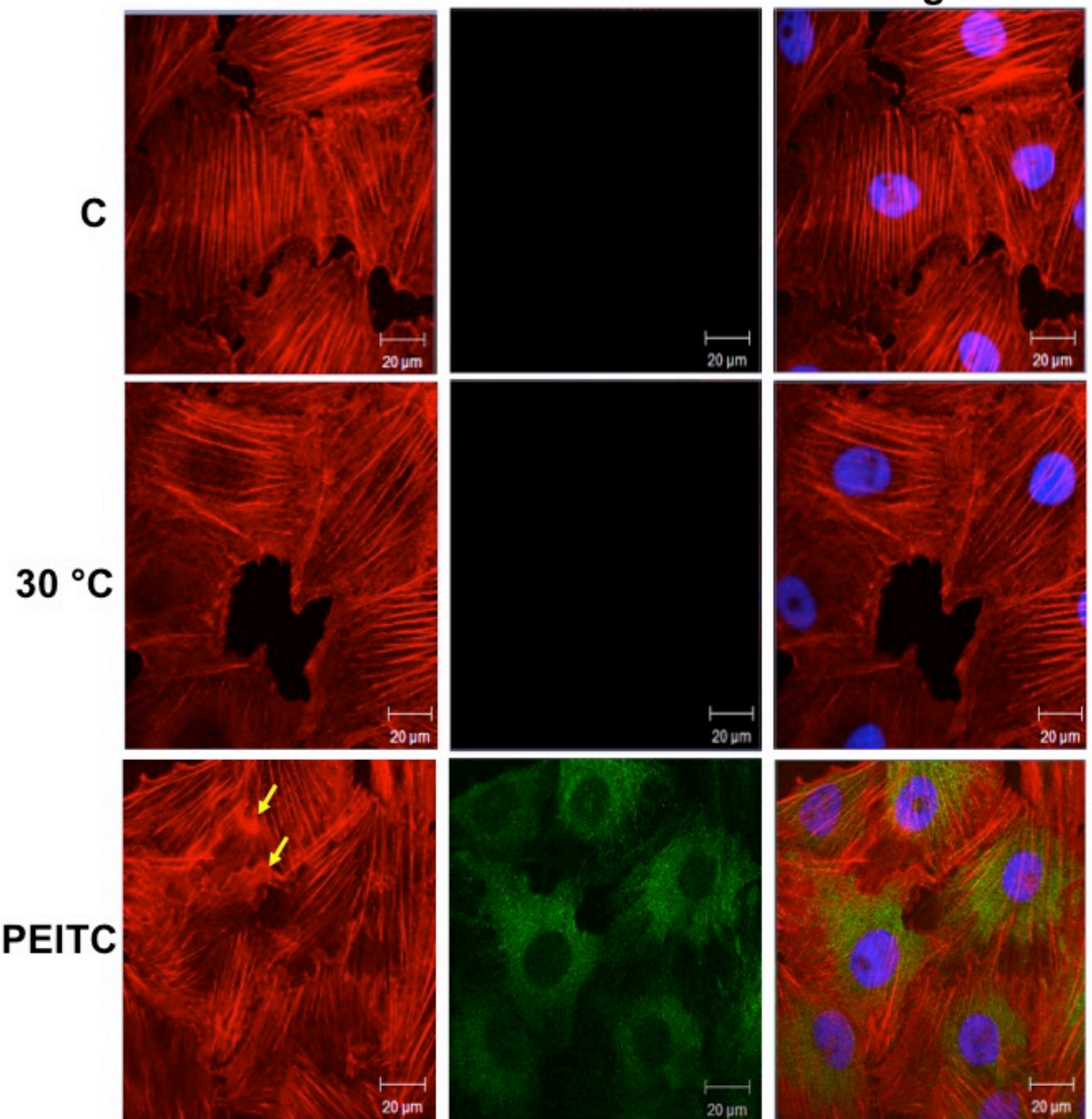

PEITC

$20 \mu \mathrm{m}$
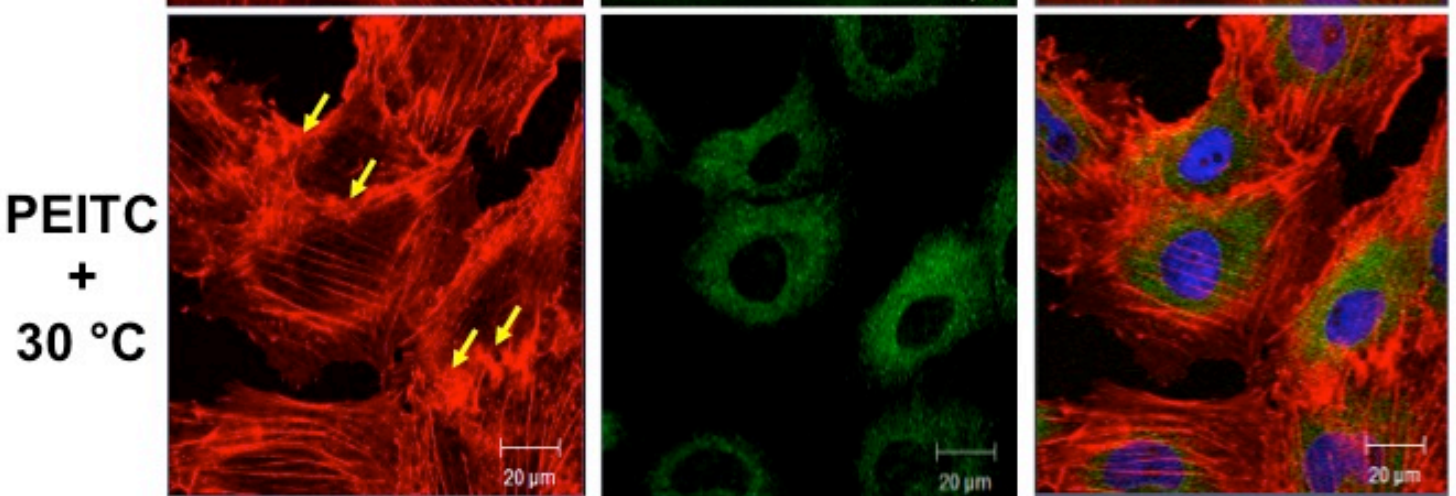
Fig. 5 Khamis and Heikkila
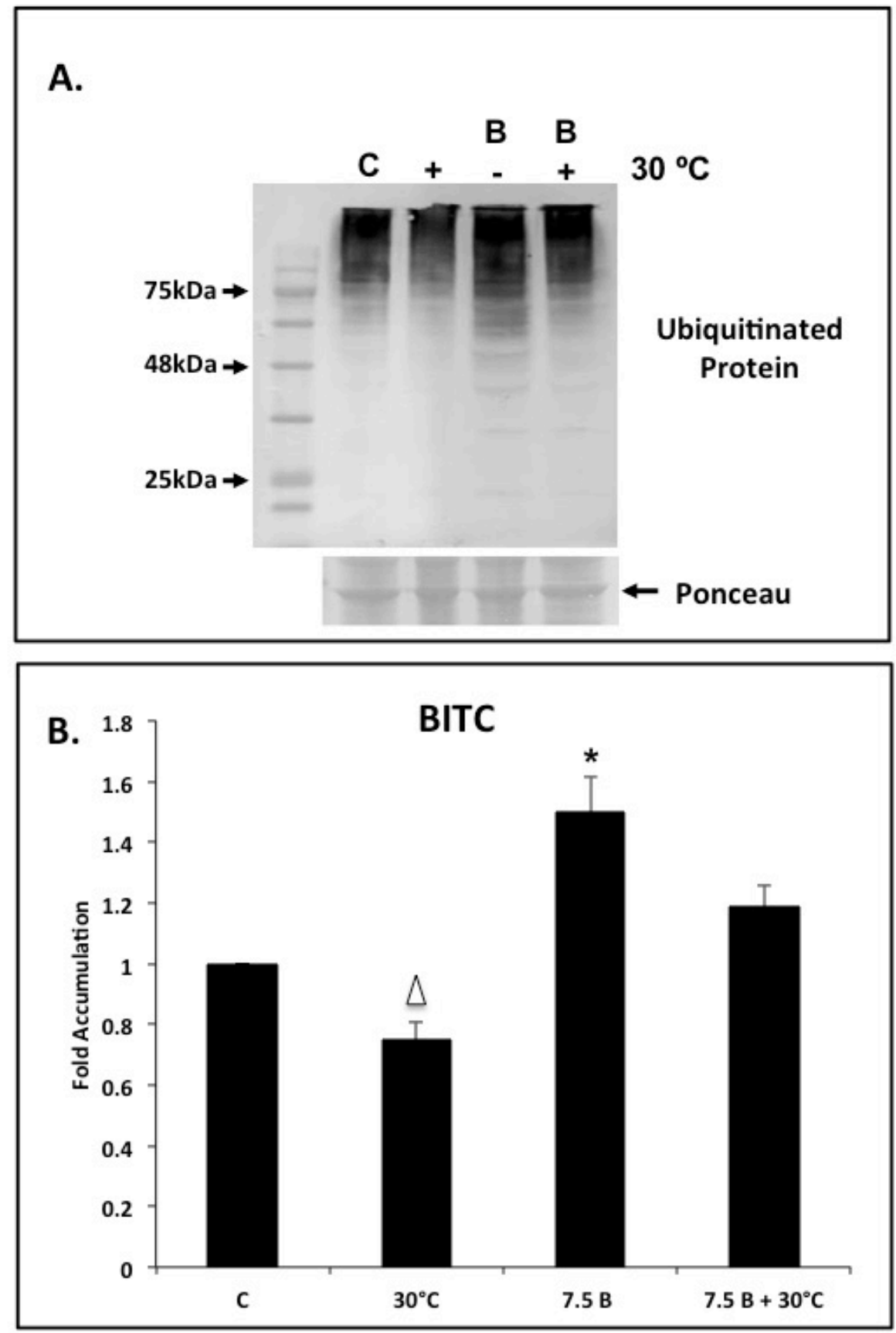
Fig. 6 Khamis \& Heikkila

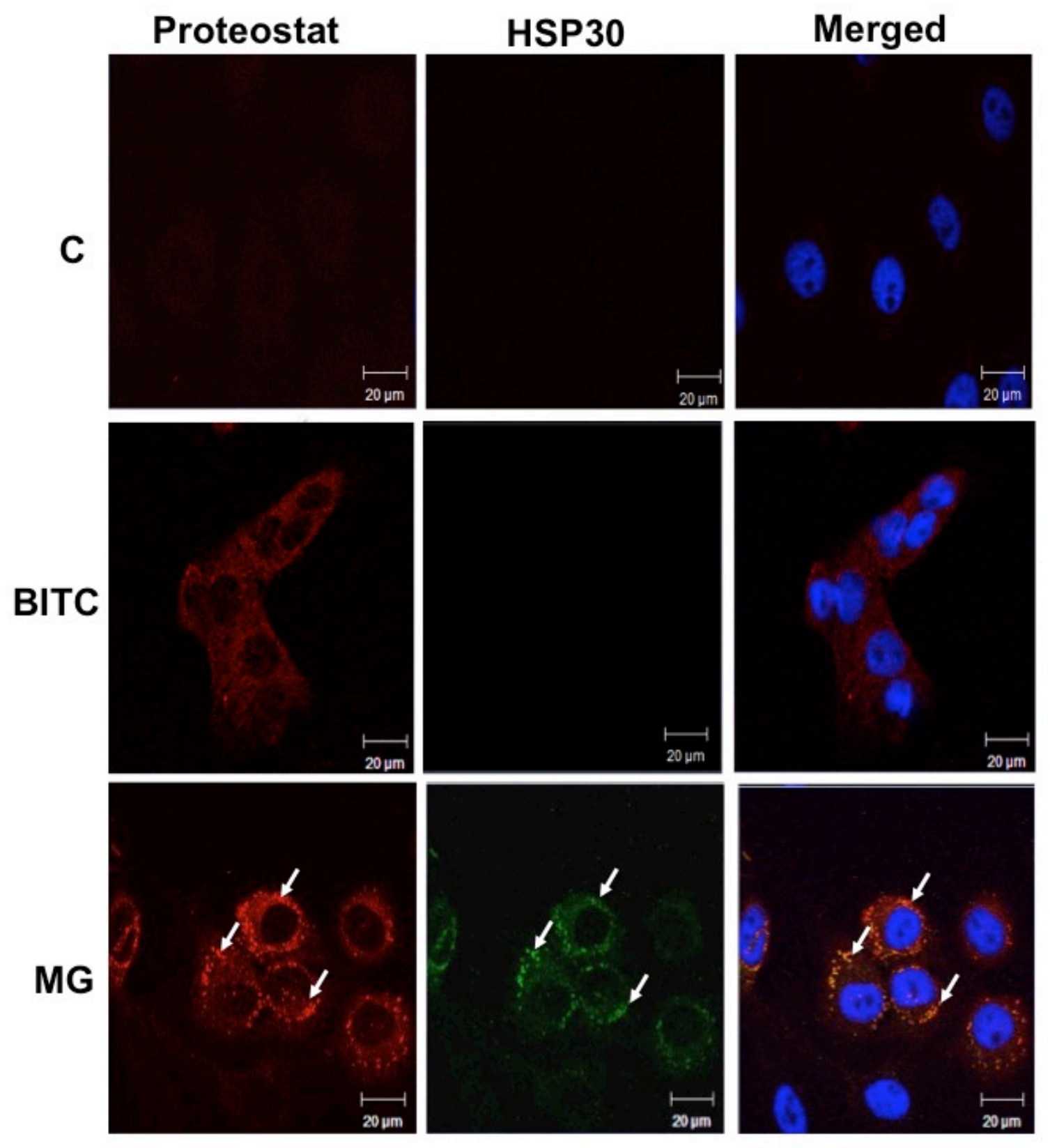


Fig. 7 Khamis \& Heikkila

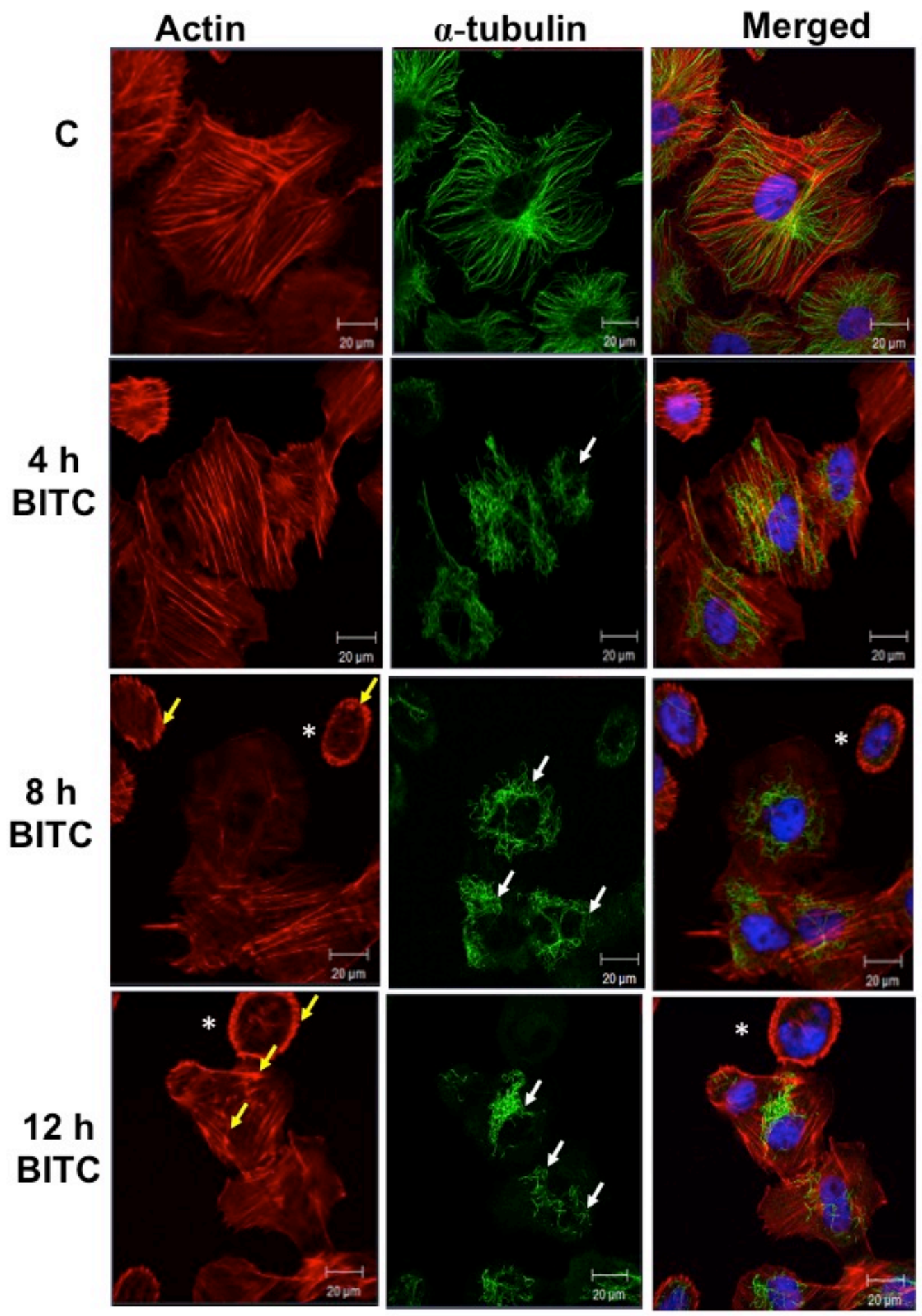


Fig. 8 Khamis \& Heikkila
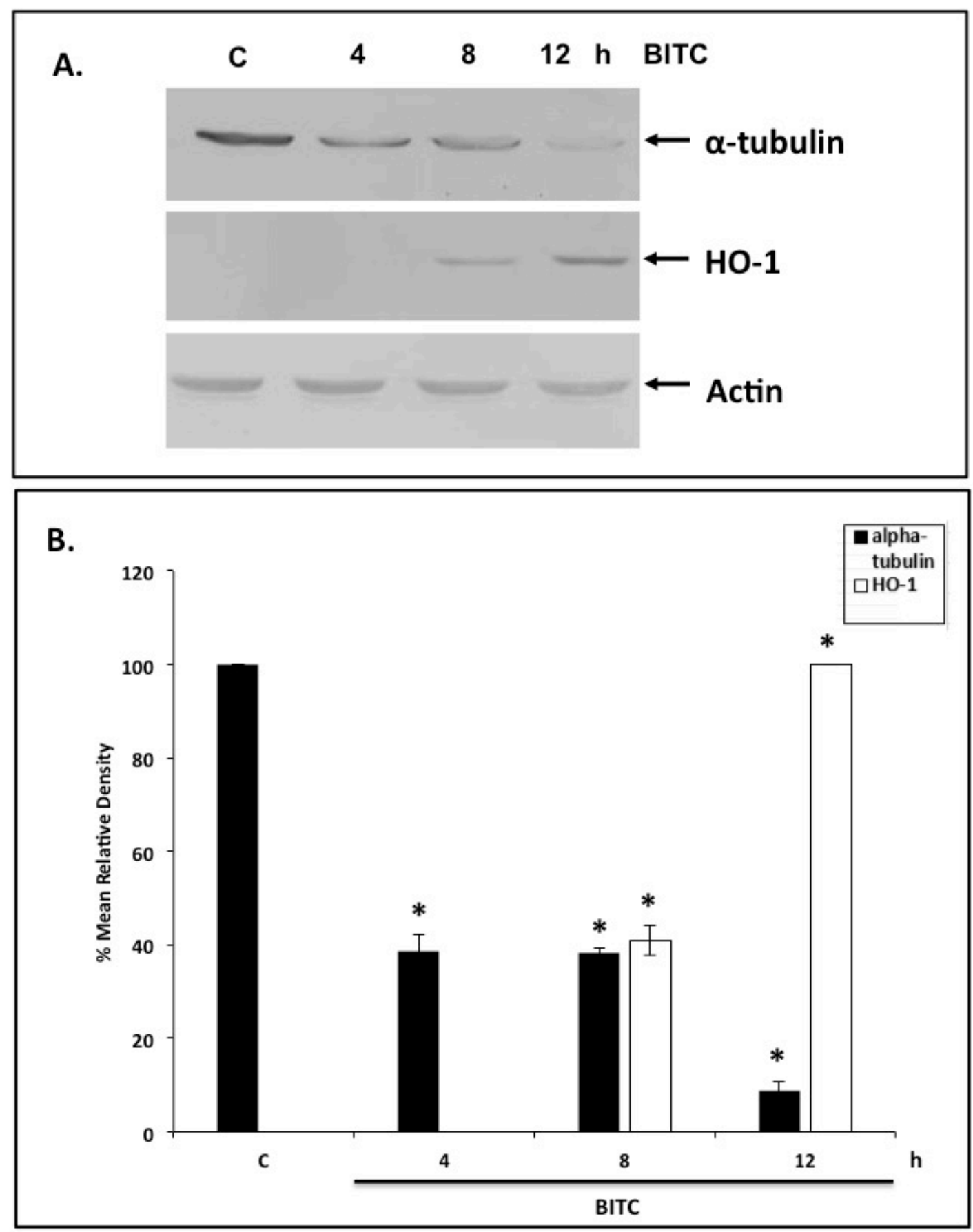
Fig. 9 Khamis \& Heikkila
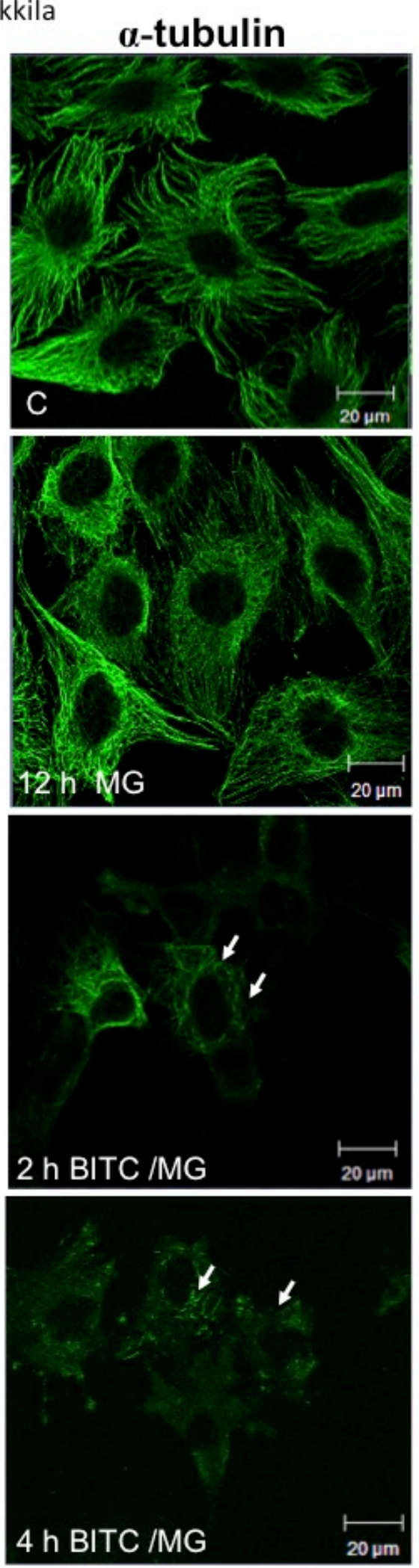

Proteostat

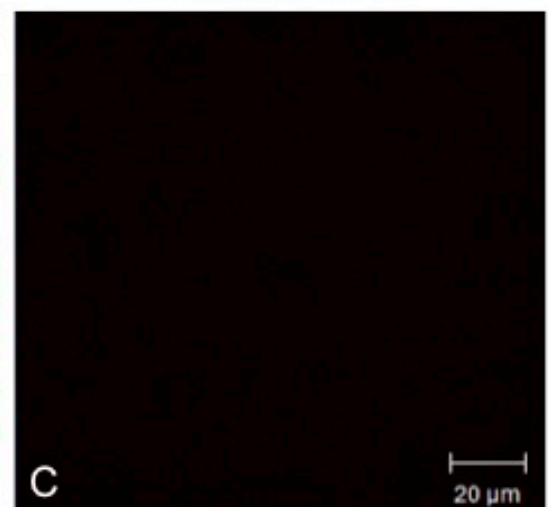

$12 \mathrm{~h}$ MG

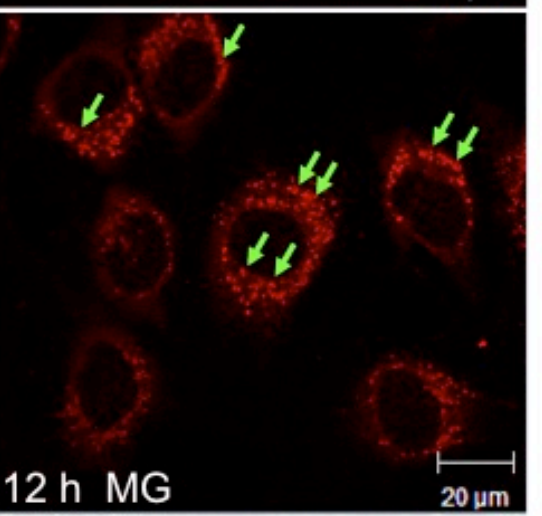

$2 \mathrm{~h} \mathrm{BITC} / \mathrm{MG}$

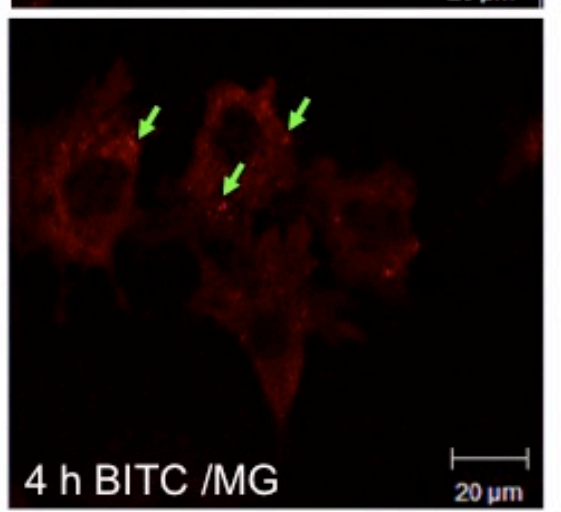

